\title{
DE SÚBDITOS A CIUDADANOS. LA EMERGENCIA DE NUEVAS PRÁCTICAS ELECTORALES EN EL MADRID DE $1868^{1}$
}

\author{
From Subjects to Citizens. The Emergence of New \\ Electoral Practices in Madrid 1868
}

\author{
Santiago de Miguel Salanova \\ sdmiguel@ghis.ucm.es \\ Université Paris IV-Sorbonne. France \\ Fecha de recepción: 06/09/2016 \\ Fecha de aceptación: 02/02/2017
}

RESUMEN: Este artículo pondera la trascendencia que la Revolución de 1868 tuvo en la aparición de nuevos comportamientos políticos en Madrid a través de un estudio de caso concreto: las elecciones municipales celebradas en diciembre de ese año, primeras en las que los habitantes de la capital elegían democráticamente a sus representantes en el consistorio tras la aprobación del sufragio universal masculino. A partir de una documentación de archivo inédita (actas del Ayuntamiento Popular de Madrid y actas de los mencionados comicios municipales), se analizará el proceso de aprendizaje del nuevo derecho electoral por parte de la población madrileña. Dentro de esta temática se determinarán las principales debilidades del sistema recién estrenado, visibles en la compleja organización técnica de la consulta, y el disperso panorama existente en las tendencias de voto, más proclive a favorecer a los candidatos a las concejalías por el prestigio social acumulado durante el proceso revolucionario que por su adscripción política e ideológica.

Palabras clave: Revolución de 1868; sufragio universal; Madrid; elecciones municipales.

${ }^{1}$ Este artículo ha sido posible gracias al trabajo realizado por el Grupo de Investigación de la UCM Historia de Madrid en la edad contemporánea, n. ref.: 941149, que ha contado con la financiación del proyecto nacional I+D «La sociedad urbana en la España del primer tercio del siglo xx. Madrid y Bilbao, vanguardia de la modernidad, 1900-1936», en el marco del Programa Estatal de Fomento de la Investigación Científica y Técnica de Excelencia del Ministerio de Economía y Competitividad (ref. HAR2015-65134-C2-1-P). 
ABSTRACT: This article oversees the importance that the Revolution of 1868 in Spain had on the emergence of new political and electoral practices through a study case: the municipal elections held in December of that year in Madrid. That was the first time in which the inhabitants of the city elected democratically their representatives in the City Council, after the adoption of universal male suffrage. Drawing on an unpublished documentation files (proceedings of the City Council of Madrid in 1868 and of the aforementioned local elections), our purpose is to analyse the process of learning of the new electoral law by the population of this city. Within this framework, we will identify the main weaknesses of the newly electoral system, visible in the complex technical organization of the elections and the scattered panorama in voting trends, more inclined to favour the local candidates in order to the political and social prestige accumulated during the revolutionary process.

Keywords: Revolution of 1868; universal suffrage; Madrid; local elections.

SUMARIO: 1. Introducción. 2. Los nuevos horizontes de la administración municipal en el Madrid de 1868. 3. La organización de la campaña electoral. 4. Los resultados electorales. 5. Conclusiones. 6. Bibliografía.

\section{INTRODUCCIÓN}

El 24 de diciembre de 1868, el diario The Times hizo referencia a las elecciones municipales recién celebradas en Madrid. Sus habitantes acababan de votar por primera vez amparados por el decreto que establecía el sufragio universal masculino el 9 de noviembre y el periódico destacó el ambiente que se respiraba en la ciudad durante los comicios, con casi cien colegios electorales en los que llegaron a congregarse cifras cercanas al millar de votantes. Sin embargo, los dos hechos más significativos de esa cita fueron otros. Primero, el escaso debate político al que dio lugar, visible en el tímido empeño que pusieron los partidos al promocionar sus candidaturas. Y segundo, la falta de costumbre de los madrileños en el ejercicio del sufragio, evidente en el caso de los vecinos no alfabetizados que "se limitaron a coger las papeletas que quedaban a su disposición en los colegios para depositarlas en las urnas de las mesas electorales»².

Algunas de las afirmaciones del diario británico resultan ciertas a la luz de lo demostrado por los trabajos realizados sobre esas elecciones ${ }^{3}$. En el caso de Madrid, ya ha quedado constancia de que en los barrios del Ensanche Norte se caracterizaron por una baja participación, una nula pugna política entre las candidaturas y una tipología ambigua de electores en cuanto a su comportamiento a pie de urna ${ }^{4}$. La consideración de estos comicios como mero ensayo para los de Cortes de 1869

2 The Times, 24 de diciembre de 1868.

${ }^{3}$ Se coincide en este trabajo con los argumentos señalados por Gutiérrez y Zurita para explicar el tratamiento superficial de estos comicios (falta de datos, carácter administrativo y posición intermedia entre dos acontecimientos de mayor relevancia como la formación de las juntas revolucionarias y las elecciones generales de 1869). En Gutiérrez, y Zurita, 1999.

${ }^{4}$ Pallol, 2013. 
(celebrados tres semanas después) y como instrumento de legitimación del nuevo poder revolucionario es acertada si tenemos en cuenta que los concejales electos en esta cita se caracterizaron por una presencia relevante en las jornadas de septiembre en Madrid y por su protagonismo en las juntas revolucionarias de distrito formadas a continuación ${ }^{5}$. Sin embargo, aún quedan por dilucidar aspectos relacionados con el cambio que se acababa de operar en Madrid y con la incipiente movilización política de sus habitantes.

Hasta el momento, la historiografía especializada en la Revolución de 1868 y en el Sexenio Democrático no ha planteado un estudio monográfico relacionado con esta temática en el caso de la capital española, al contrario de lo que ha ocurrido con otros marcos geográficos como Ciudad Real, Barcelona, Murcia, Albacete, Sevilla, Aragón y Castilla y León ${ }^{6}$. A nivel electoral, los trabajos más relevantes se han centrado en el análisis de comicios generales como los ya citados de 18697, salvo contadas excepciones ${ }^{8}$. En este sentido, el presente artículo buscará aportar nuevas luces sobre la aparición de nuevos comportamientos políticos en Madrid conectados con las nuevas y heredadas dinámicas de la ciudad a través de un estudio de caso concreto: las elecciones municipales de diciembre de 1868.

\section{LOS NUEVOS HORIZONTES DE LA ADMINISTRACIÓN MUNICIPAL EN EL MADRID DE 1868}

A diferencia de lo ocurrido en decenios anteriores, los madrileños tuvieron voz y voto en el nuevo régimen político de 1868 desde un primer momento ${ }^{9}$. Hasta el advenimiento de la Gloriosa, el derecho electoral quedó prácticamente restringido al que Rosanvallon definió como "ciudadano propietario», receptor del voto en función de criterios fiscales ${ }^{10}$. La Ley de Ayuntamientos de 1845 fijaba la base electoral municipal del país antes de las jornadas revolucionarias determinando, para los núcleos poblacionales de más de 20.000 habitantes, un total de 1.767 electores (los mayores contribuyentes), a los que se sumaban la decimotercera parte del número de vecinos excedente de esa cifra. Esta regla dejaba la intervención municipal de Madrid en manos de los más acomodados, solo secundados por

${ }^{5}$ De la Fuente, 2000.

${ }^{6}$ Gil Novales, 1980; Serrano, 1992, 1995; Villena, 1997; Janué, 2002; Navarro, 2004); Jerez, 2008 y Arias, 2010.

7 Bahamonde, 1976; Fernández, 2003.

8 Pérez Roldán, 2001 y Pallol, 2013.

9 Sobre la capacidad electoral antes de 1868 véanse: Flaquer, 2007; Sierra, Peña, y Zurita, 2010.

${ }^{10}$ Rosanvallon, 1992, 1998. 
quienes formaran parte de las llamadas «capacidades». Entre estos se encontraban individuos pertenecientes a la Academia Española de la Historia y de San Fernando, doctores y licenciados, individuos de los cabildos eclesiásticos, curas párrocos y sus tenientes, magistrados, jueces de primera instancia, promotores fiscales, empleados activos, cesantes o jubilados cuyo salario anual alcanzara los 10.000 reales, oficiales en activo o retirados del Ejército y de la Armada, abogados, médicos, cirujanos y farmacéuticos con dos años de ejercicio, arquitectos, pintores y escultores titulados en alguna de las academias de nobles artes y maestros de enseñanza pública ${ }^{11}$. Las causas privativas del derecho electoral se reforzaban con los requisitos fijados para el acceso a cargos edilicios. El artículo 20 de la ley de 1845 expresaba que en los municipios que sobrepasaran el millar de vecinos solo eran elegibles la mitad de los contribuyentes. En este caso, únicamente el poder adquisitivo del elector podía convertirle en candidato a concejal, pues las exigencias académicas, eclesiásticas y militares dejaban de advertirse ${ }^{12}$.

La permisividad para una intervención gubernativa indiscriminada en el procedimiento electoral municipal era evidente. En Madrid, las listas de electores y elegibles las formaba el alcalde asociado a dos concejales y a los dos mayores contribuyentes de la ciudad, designados de acuerdo con los datos de contribuciones y repartimientos de Hacienda. Las reclamaciones por causas de inclusión u omisión indebida de electores debían dirigirse en primer término al alcalde, si bien era el jefe político de la provincia quien validaba el escrutinio tras las votaciones, teniendo además la potestad de ordenar la repetición de los comicios si lo juzgaba oportuno.

En estas circunstancias, es lógico presuponer la escasa neutralidad de las elecciones municipales celebradas en Madrid hasta la implantación del sufragio universal masculino ${ }^{13}$. Cuando se acercaban estas citas, la prensa daba a conocer de manera escueta a los elegibles de cada partido y hacía un estado de las secciones que correspondían a cada distrito. Los progresistas en la oposición se limitaban a lanzar tímidas circulares desde su comité central, defendiendo el papel vital de los ayuntamientos en la organización de la vida social. Sus órganos de prensa ponían en liza las señales más evidentes del fraude electoral, denunciando los mecanismos planteados para el falseamiento del sistema representativo ${ }^{14}$. Sus funciones, además, no dejaban de ser laxas y mayoritariamente orientadas a la redacción de bases para la organización del partido, la selección de candidatos y el envío de personas de influencia a ciertos distritos ${ }^{15}$.

11 Gaceta de Madrid, 15 de enero de 1845.

12 Caballero, 1999; Estrada, 1999.

13 Touya, 2002.

${ }^{14}$ Véanse, a modo de ejemplo, las actas de las elecciones municipales de 1862 en: Archivo de Villa de Madrid (desde ahora, AVM), Secretaría, expediente, 4-188-10.

${ }^{15}$ Romeo, 2013. 
El carácter restringido del cuerpo electoral queda reflejado en el hecho de que la mayoría de los distritos madrileños contaron con menos de un millar de electores, si bien eran los que tenían un carácter popular más arraigado los que presentaban las cifras más bajas por la menor concentración de contribuyentes y capacidades. Tomando como referencia las elecciones municipales de 1866 (últimas que se celebraron con el sufragio censitario operativo antes de la revolución de 1868), se observa una cifra de poco menos de 11.000 electores en Madrid para una población de 282.976 habitantes, excluyendo a quienes estaban presentes en la ciudad en calidad de acuartelados ${ }^{16}$.

Tabla 1. Elecciones municipales celebradas en Madrid entre 1860 y 1866

\begin{tabular}{l|l|l|l|l|l|l|l|l|l|l|l|l}
\hline \multirow{2}{*}{ Distrito } & \multicolumn{4}{|c|}{ No electores } & \multicolumn{4}{c|}{ Electores que votan } & \multicolumn{3}{c|}{ Participación electoral (\%) } \\
\cline { 2 - 12 } & $\mathbf{1 8 6 0}$ & $\mathbf{1 8 6 2}$ & $\mathbf{1 8 6 4}$ & $\mathbf{1 8 6 6}$ & $\mathbf{1 8 6 0}$ & $\mathbf{1 8 6 2}$ & $\mathbf{1 8 6 4}$ & $\mathbf{1 8 6 6}$ & $\mathbf{1 8 6 0}$ & $\mathbf{1 8 6 2}$ & $\mathbf{1 8 6 4}$ & $\mathbf{1 8 6 6}$ \\
\hline Palacio & 995 & 1.321 & 1.102 & 1.180 & 363 & 353 & 373 & 347 & 36,48 & 26,72 & 33,85 & 29,41 \\
Universidad & 1.176 & 1.353 & 1.076 & 1.359 & 550 & 509 & 604 & 473 & 46,77 & 37,62 & 56,13 & 34,81 \\
Correos* & 715 & 792 & 971 & 928 & 381 & 373 & 498 & 260 & 53,29 & 47,10 & 51,29 & 28,02 \\
Hospicio & 1.001 & 1.133 & 1.104 & 1.366 & 460 & 517 & 594 & 329 & 45,95 & 45,63 & 53,80 & 24,08 \\
Aduana* & 978 & 1.152 & 1.426 & 1.281 & 344 & 347 & 266 & 313 & 35,17 & 30,12 & 18,65 & 24,43 \\
Congreso & 913 & 1.112 & 1.036 & 1.282 & 430 & 405 & 436 & 420 & 47,10 & 36,42 & 42,08 & 32,76 \\
Hospital & 935 & 784 & 1.060 & 979 & 436 & 304 & 396 & 245 & 46,63 & 38,78 & 37,36 & 25,03 \\
Inclusa** & 692 & 841 & - & 735 & 314 & 412 & - & 174 & 45,38 & 48,99 & - & 23,67 \\
Latina & 562 & 682 & 831 & 724 & 416 & 242 & 232 & 202 & 74,02 & 35,48 & 27,92 & 27,90 \\
Audiencia & 812 & 806 & 851 & 917 & 288 & 262 & 258 & 164 & 35,47 & 32,51 & 30,32 & 17,88 \\
\hline Total & 8.779 & 9.976 & 9.457 & 10.691 & 3.972 & 3.724 & 3.657 & 2.927 & 45,24 & 37,33 & 38,67 & 27,38 \\
\hline
\end{tabular}

Leyenda (*): En las elecciones municipales de 1864 y 1866, Correos y Aduana pasan a denominarse Centro y Buenavista respectivamente; $\left({ }^{* *}\right)$ : La falta de datos para Inclusa en 1864 se debe a la ausencia de una convocatoria electoral en este distrito. Fuente: AVM, Secretaría, 10-36-42.

Uno de los objetivos prioritarios de los revolucionarios de 1868 fue amplificar el derecho electoral de la población. El 30 de septiembre de 1868, la Junta Central Revolucionaria interina de Madrid publicó un bando con el que instaba a los vecinos de cada barrio a elegir las juntas definitivas de sus distritos «libre $y$ universalmente», en el marco de un proceso de transferencia pacífica del poder ${ }^{17}$.

${ }^{16}$ Las cifras poblacionales en: De Bona, 1996.

17 La Junta Central Revolucionaria interina se dividía en cuatro secciones (recepción, gobernación, hacienda y armamento y defensa), contabilizándose junto a ella en Madrid catorce juntas revolucionarias de distritos o barrios que contribuyeron a mantener el orden público recibiendo inspiraciones de la anterior. Las juntas en cuestión fueron: distrito de Palacio (teatro de Oriente), distrito de Buenavista (Ateneo, en calle Montera 21), distrito de la Audiencia (callejón del Infierno), distrito de Congreso (plaza de Matute), distrito de Centro (calle Mayor 18), 
Era el primer paso para legitimar los acontecimientos revolucionarios a través de la voluntad popular y el primer encuentro con una forma de representatividad política no restringida ${ }^{18}$. Careciendo de una ley que determinara de manera efectiva el mecanismo para regular el voto, la junta interina precisó las instrucciones básicas para ejercer el nuevo derecho. La elección esperaba celebrarse el 1 de octubre previa reunión en los barrios de sus vecinos, que habrían de designar por el método más breve y expedito un presidente de mesa y cuatro secretarios escrutadores de entre todos ellos para verificar la elección. El bando certificó el derecho de todos los vecinos mayores de 25 años a emitir su voto sin distinción de clase. En cada papeleta debían figurar tres nombres propuestos como candidatos propietarios (de los que saldrían los treinta que formarían la junta definitiva) y tres como candidatos suplentes. El acta electoral de cada barrio, firmada por el presidente y los secretarios, sería entregada a la junta de distrito, responsable de emitir el escrutinio final. Aunque no se conservan documentos que verifiquen su formación mediante el procedimiento del sufragio universal, la Junta Superior Revolucionaria de Madrid no debe ser pasada por alto porque un número importante de sus integrantes figuraron después como candidatos a las concejalías en las elecciones municipales ${ }^{19}$.

El carácter precipitado de la elección puede comprobarse en las comunicaciones dirigidas a la junta interina por parte de algunas de las formadas en los distritos, que recalcaron la imposibilidad de que la votación pudiera verificarse en una única jornada ${ }^{20}$. Las escasas reseñas de prensa sobre esta cita también permiten escudriñar su desacompasada organización en los distritos, deudora de la carencia absoluta de una cartografía electoral eficiente. En el de Universidad, sus diez barrios se agruparon en tres circunscripciones con tres colegios electorales distintos en los que se desarrollaron votaciones simultáneas. En Audiencia, los medios preparatorios para la elección fueron fragmentarios si tenemos en cuenta las reuniones que se celebraron entre los electores de los barrios de Progreso y

distrito de la Inclusa (calle de Embajadores frente a la de los Abades), distrito del Hospital (calle del Ave María esquina a San Simón), barrio de Pozas (café de Pozas), junta de Santo Domingo (calle Ancha de San Bernardo 2), distrito de la Universidad (ministerio de Gracia y Justicia), junta de Antón Martín (teatro de Variedades), distrito de la Latina (plaza de San Millán 11), Plaza de la Cebada (ídem) y afueras de Atocha (Hospital General). Véase: Alfaro, 1871-1876, p. 58.

${ }_{18}$ Según De la Fuente, fueron veinte las capitales de provincia que organizaron elecciones para la formación de juntas revolucionarias definitivas. Algunas de ellas, como por ejemplo Barcelona, fijaron la edad para votar en 21 años y señalaron normas más precisas que las vistas en Madrid para la organización de la jornada electoral. Véanse: De la Fuente, 2000, p. 124 y Rubio, 1869, pp. 373-374.

19 La composición de la Junta Superior Revolucionaria de Madrid en: AVM, Secretaría, expediente, 4-406-21.

${ }^{20}$ La Correspondencia de España, 30 de septiembre de 1868. 
Relatores en la casa de Manuel Becerra, y lo mismo se puede decir de Buenavista, donde los barrios de Plaza de Toros y Salamanca celebraron una votación separada del resto del distrito. Sin embargo, esta no fue la tónica generalizada de la jornada, ya que en la medida de lo posible se buscó respetar la circunscripción de votación que se mantendría en las siguientes elecciones ${ }^{21}$. En cuanto a la participación, resulta poco creíble la cifra de 40.000 electores que La Época apuntó en sus páginas ${ }^{22}$. El número de personas que acudió a votar no llegaría siquiera a la mitad, teniendo en cuenta que en distritos como Latina, Palacio o Buenavista apenas votaron 2.000 habitantes ${ }^{23}$.

La Junta Superior Revolucionaria de Madrid formada tras esta elección (difícilmente catalogable como la primera muestra genuina de la expresión del sufragio universal) se consagró inicialmente a la organización de la vida social de la flamante ciudad revolucionaria, velando por el restablecimiento del movimiento ordinario de los intereses y relaciones cotidianas de sus habitantes. Teniendo en cuenta la situación social presentada en una ciudad plagada de inmigrantes y jornaleros en paro ${ }^{24}$, una de las primeras medidas que tomó fue asegurar trabajo para obreros y artesanos promocionando las obras que hubiesen quedado interrumpidas por falta de recursos económicos en años anteriores. Su objetivo inmediato fue facilitar la intervención de albañiles, carpinteros, cerrajeros y canteros en la edificación de fincas, buscando, en adición, la cooperación de propietarios que tuvieran pendientes "construcciones suspendidas o no principiadas por dificultades que con buena y decidida voluntad se vencen instantáneamente ${ }^{25}$.

Además de para estipular un jornal de siete reales y medio a todos los trabajadores anteriormente citados, la reunión de la junta celebrada el 8 de octubre de 1868 sirvió para la apertura de un anticipo reintegrable entre los vecinos que permitiera la ocupación de quienes desearan ganar honradamente su subsistencia. Ese anticipo se fijaba en una cantidad de un millón de escudos y sería reintegrado a medio plazo a través de la venta de una serie de bienes. Entre ellos destacaban los valores que pertenecieran al Ayuntamiento por el derribo del Pósito, los que resultaran de la demolición del Convento de San Martín, los solares de la Fuente Castellana y de la calle de Preciados, los 700.000 pies de terreno que tras los trabajos de explanación quedaran útiles en el barrio de Argüelles y los terrenos adquiridos para la Exposición Hispano-Americana.

${ }^{21}$ Las crónicas de esta cita electoral en: La Iberia, Las Novedades, La Correspondencia de España y La Esperanza, 1-3 de octubre de 1868.

22 La Época, 2 de octubre de 1868.

${ }^{23}$ La lberia, 4 de octubre de 1868.

${ }^{24}$ Pallol, Carballo y Vicente, 2010.

${ }^{25}$ La Iberia, 9 de octubre de 1868. 
El 9 de octubre fue el primer día de alistamiento para trabajar en las obras municipales, dotándose de ocupación a 5.000 obreros $^{26}$. Cuatro días más tarde, se determinó que la admisión de operarios se verificase en las tenencias de alcaldía de los distritos, siendo requisito indispensable para aquellos presentar cédulas de vecindad, certificados del alcalde de barrio o papeletas emitidas por la junta revolucionaria del distrito correspondiente ${ }^{27}$. Paralelamente, las juntas elegidas por sufragio universal en los distritos dieron pábulo a iniciativas para socorrer a los pobres de cada circunscripción (donativos de pan y bonos de alimentos) y clamaron por la necesidad de derribar los conventos que todavía existían en la ciudad, no solo como medida para incrementar la riqueza pública, sino también para sustituirlos por plazas, mercados y otros espacios de desahogo favorables a la higiene pública ${ }^{28}$.

Las anteriores tareas quedaron centralizadas en el Ayuntamiento Popular de Madrid designado por la Junta Superior Revolucionaria el 9 de octubre de 1868. En el nombramiento de sus regidores incidieron la necesidad de desarrollar una administración municipal "pura, limpia y activa» y «su cooperación para el triunfo del alzamiento nacional, sus conocimientos administrativos y específicos de los distritos que se les confiaba» ${ }^{29}$. Constituido con carácter interino el consistorio y asumida su presidencia por Nicolás María Rivero, los cometidos fundamentales de la institución debían ser el mantenimiento del orden, la protección de la propiedad y seguridad individual, la resolución de las cuestiones graves que se presentaran en los negocios encomendados a su administración y facilitar trabajo a todos aquellos que lo necesitaran.

Las comisiones formadas en el seno del consistorio plantearon iniciativas decisivas para asegurar el cambio de escala del Madrid revolucionario. Esto exigía transformar el régimen de tenencia de los cementerios (dejándolos en dependencia exclusiva del municipio $)^{30}$, derribar la anti-higiénica cárcel del Saladero ${ }^{31}$, dar una salida provechosa al expediente de reforma instruido sobre el plano del Ensanche de Madrid (aprobado desde 1860 pero paralizado en años posteriores) ${ }^{32}$, construir mercados de abastos aptos para los nuevos tiempos ${ }^{33}$, y mejorar las condiciones de los locales destinados a escuelas públicas (facilitando además medios de

${ }^{26}$ La Correspondencia de España, 9 de octubre de 1868.

27 La Correspondencia de España, 13 de octubre de 1868.

${ }^{28}$ El Imparcial, La Iberia y La Discusión, 5-10 de octubre de 1868.

${ }^{29}$ AVM, Libro de Actas del Ayuntamiento Popular de Madrid, 10 de octubre de 1868.

${ }^{30}$ AVM, Libro de Actas del Ayuntamiento Popular de Madrid, 14 de octubre de 1868.

${ }^{31}$ AVM, Secretaría, expediente 6-6-6, Expediente de derribo de la cárcel del Saladero, 18681870.

32 AVM, Libro de Actas del Ayuntamiento Popular de Madrid, 11 y 14 de octubre de 1868.

${ }^{33}$ AVM, Libro de Actas del Ayuntamiento Popular de Madrid, 7, 14 y 17 de noviembre de 1868. 
instrucción para las clases trabajadoras $)^{34}$, sin olvidar las disposiciones para cambiar la toponimia del callejero que aludiera al pasado monárquico y las obras orientadas a rememorar el pasado liberal (levantamiento de una estatua conmemorativa de Juan Álvarez de Mendizábal en la plaza del Progreso) $)^{35}$.

El nuevo consistorio también puso un empeño crucial en la organización de la vida laboral asumiendo las tareas inicialmente realizadas por la Junta Superior Revolucionaria. Salieron a relucir ciertos problemas dentro de este escenario relacionados con la actitud de algunos operarios de fábricas y talleres, que abandonaban su trabajo para ocuparse en las obras municipales, guiados por la ilusoria esperanza de alcanzar más beneficios económicos. Esta situación llevó a establecer algunas disposiciones para conseguir que la promoción de obras favoreciera únicamente y exclusivamente a los jornaleros carentes de recursos, obligándose a los dueños de fábricas, tahonas, carpinterías, herrerías y establecimientos similares a dar parte a las alcaldías de barrio de los operarios y dependientes que abandonaban sus puestos con objeto de dedicarse a los trabajos municipales para que se pudieran transmitir, posteriormente, a los maestros de obras, con el fin de no admitir a las personas incluidas en esas listas ${ }^{36}$.

Sin embargo, el carácter provisional del consistorio exigía otra tarea fundamental: dilucidar el procedimiento para la formación del futuro ayuntamiento democrático. Una circular redactada por la Junta Superior del Gobierno Provisional el 14 de octubre de 1868 indicó el camino a seguir, precisando que las corporaciones municipales debían organizarse mediante «elecciones que respetaran los principios revolucionarios $»^{37}$. El objetivo de democratizar la representatividad municipal nació de la idea de descentralización defendida por los progresistas y quedó perfectamente expresada en el suplemento extraordinario publicado por el diario Las Novedades el 29 de septiembre de $1868^{38}$. Era preciso regenerar una autoridad municipal «falseada y utilizada en provecho propio por los Borbones» para dar luz verde a los abusos del poder centralizado. Debía rescatarse la función primigenia de

${ }^{34}$ AVM, Libro de Actas del Ayuntamiento Popular de Madrid, 14 y 24 de octubre de 1868.

35 Este objetivo ya se había planteado en Madrid en los momentos iniciales del Bienio Progresista, como se demuestra en el trabajo de Zurita (2014).

${ }^{36}$ AVM, Secretaría, expediente 4-406-17, Bando sobre alistamiento de braceros del 16 de octubre de 1868; AVM, Secretaría, expediente 4-406-14, Bando sobre la concesión de actividad para braceros del 21 de octubre de 1868 y AVM, Secretaría, expediente 4-406-16, Bando que alude a los operarios de fábricas que abandonan los lugares en que trabajan para ocuparse en las obras municipales (30 de octubre de 1868).

37 Gaceta de Madrid, 14 de octubre de 1868.

${ }^{38}$ Según Ibo Alfaro, el citado suplemento, considerado como el verdadero programa de la revolución de septiembre por proclamar la libertad en su más amplio sentido, fue escrito por los redactores de Las Novedades veinte días antes de estallar el movimiento. En: Alfaro, 1871-1876, p. 40. 
un municipio que era la base de las libertades públicas y del bienestar y devolver al pueblo su derecho a decidir sobre la beneficencia, la enseñanza, las obras públicas y los fondos presupuestarios que organizaba aquel.

Los señalados propósitos adquirieron carta de naturaleza el 21 de octubre con un Real Decreto que ponía en funcionamiento dos nuevas leyes para la organización provincial y municipal del país ${ }^{39}$. Los capítulos de la segunda tuvieron una importancia decisiva en la organización técnica de las elecciones celebradas en lo sucesivo. El segundo sentaba las bases para la definición del derecho electoral distinguiendo entre residentes (no inscritos en los padrones de habitantes) y vecinos (cabezas de familia que figuraban en dicha estadística con dos años de residencia). Los capítulos III y IV planteaban las reglas para la creación de ayuntamientos, renovándose sus mitades con periodicidad bienal y variando la duración del mandato de alcaldes y concejales entre dos años para los primeros y cuatro para los segundos. En cuanto al escrutinio, la modificación más importante tuvo que ver con el sistema determinado para la elección de alcaldes, que pasaba a realizarse en segundo grado ${ }^{40}$.

La ruptura con la legislación electoral moderada se completó con el decreto sobre el ejercicio del sufragio universal de 9 de noviembre de 1868, que situaba a España en una de las primeras posiciones en cuanto respecta a la declaración de este derecho por detrás de Francia, Suiza, Grecia y Alemania ${ }^{41}$. Concentraba en un único texto las disposiciones referidas a elecciones generales, provinciales y municipales, buscando fomentar entre los vecinos comportamientos unívocos para comicios venideros ${ }^{42}$. Podrían ejercer el sufragio todos los vecinos mayores de 25 años (excepto los privados del mismo por causas penales o económicas, art. 2), siendo su capacidad electoral acreditada mediante cédulas talonarias de vecindad repartidas por el alcalde de distritos y barrios a los electores en sus domicilios. Esas cédulas incluían el nombre del elector junto a su edad, la calle donde vivía y el piso que ocupaba en su edificio de vecindad, datos que se recopilaban a partir del Padrón Municipal de Habitantes, que según la ley municipal debía cumplimentarse entre el 1 de octubre y el 1 de noviembre de cada año. Correspondiendo una hoja de empadronamiento a cada vivienda, los datos que en ella se incluían por cada cabeza de familia (edad y tiempo de residencia) jugarían un papel decisivo a la hora de otorgar el derecho al voto. El padrón era, en ese momento, la herramienta más fiable para fijar la identidad civil de cada individuo y reconocer sus cualidades políticas ${ }^{43}$.

39 Gaceta de Madrid, 22 de octubre de 1868.

40 Martínez, 1989, p. 63.

41 Noiret, 1990; Garrigou, 1991; Huard, 1991; Offerlé, 1993; Romanelli, 1998; Przeworski, 2009.

42 Gaceta de Madrid, 10 de noviembre de 1868.

${ }^{43}$ A diferencia de lo que ocurría en ciudades europeas como París, el padrón de habitantes de Madrid se redactaba con periodicidad anual, procedimiento que se mantuvo vigente hasta 1890 . 
La búsqueda de una mayor sinceridad electoral era perceptible en las decisiones adoptadas respecto a los votantes, que tenían la potestad de entablar contra el alcalde ante el juzgado de primera instancia de su distrito si se le denegaba la entrega de la cédula talonaria y en el apartado referente a la categoría de elegibles (artículo 12). A las elecciones podían presentarse como candidatos los vecinos no comprendidos en las excepciones marcadas en el artículo 2 que no desempeñaran un cargo de nombramiento gubernamental. Cambiaron también los procedimientos para la formación de las mesas electorales. En cada colegio, el alcalde del barrio donde se ubicara aquel ocuparía la presidencia en primer lugary daría paso a la apertura de una junta preparatoria electoral. Para ello, invitaba a cuatro secretarios escrutadores para el ejercicio de funciones interinas: los dos más ancianos y los dos más jóvenes de entre los electores presentes ${ }^{44}$. Acto seguido se procedería a la votación de la mesa por sufragio universal, formada por un presidente y cuatro secretarios elegidos a pluralidad de votos. Finalmente, el control de la votación se hizo más riguroso, especialmente en los aspectos relativos a las decisiones a adoptar con las papeletas que ofrecieran dudas sobre su validez, a las reclamaciones realizadas en el colegio electoral y a la confrontación del escrutinio final con el número de electores anotados en las listas.

Concluida la votación, el presidente de la mesa y los secretarios redactaban y firmaban el acta parcial por duplicado, conservando el primero un ejemplar y remitiendo otro al alcalde del distrito, acompañado por la lista de votantes. La junta de escrutinio general, formada por presidentes y secretarios de los colegios bajo la presidencia del alcalde primero, examinaba las reclamaciones realizadas por los electores, haciéndose mención expresa de las mismas en el acta final. Se trataba de una disposición fundamental, ya que por primera vez dentro del régimen electoral se permitía que los acuerdos alcanzados en las mesas pudieran objeto de revisión. Superado este trámite se publicaban las listas con los nombres de los elegidos durante tres días en las puertas de los colegios. Si surgían nuevas reclamaciones, el Ayuntamiento procedía a su resolución. Si se seguía cuestionando el acuerdo municipal, podría interponerse una nueva reclamación ante la Diputación Provincial. Esta sería la encargada de emitir un veredicto definitivo sobre la validez de las elecciones, pudiendo decidir su repetición total o parcial. Asimismo, el decreto incluía una relevante sección penal en su capítulo $\mathrm{V}$, tipificando delitos como el falseamiento del padrón y de cédulas de vecindad (artículo 121), aplicación de sufragios a favor de un candidato de manera indebida (artículo 122) y coacción de funcionarios sobre electores (artículo 123) ${ }^{45}$.

En virtud de la anterior normativa se convocaron elecciones municipales en toda España para el 1 de diciembre de 1868. Fue, sin duda, una decisión apresurada.

44 Esta solución también estuvo presente en el caso francés al decretarse el sufragio universal en 1848 (Villette, 2013, p. 210).

${ }^{45}$ Gaceta de Madrid, 10 de noviembre de 1868. 
Ya en la circular emitida por el Ministerio de la Gobernación el 10 de noviembre para convocarlas se admitía la inevitabilidad de prescindir para esa cita «de ciertas formalidades prescritas en el decreto electoral $»^{46}$. Aquellas tratarían de observarse con rigor para las decisivas elecciones a Cortes, pero la urgencia de las circunstancias no permitía que se guardasen con el mismo celo al elegir a los representantes municipales. Muchos gobernadores señalaron la imposibilidad de cumplir en tan corto espacio de tiempo con las operaciones preliminares que debían garantizar la legalidad del proceso electoral, y de manera particular, con la de imprimir y repartir el número de cédulas a que daba lugar la implantación del sufragio universal. Era muy poco tiempo para que el Ayuntamiento elaborase un padrón de casi 300.000 habitantes, solicitando con urgencia a los Juzgados de 1a Instancia datos sobre los empadronados con derecho de voto. La herencia técnica de los procesos electorales del período isabelino era inútil para adelantar tiempo, pues solo permitía aproximarse al sector censitario y capacitado de la ciudadanía política, razón por la que finalmente se decidió posponer la elección hasta el 18 de diciembre.

\section{LA ORGANIZACIÓN DE LA CAMPAÑA ELECTORAL}

Los caminos por los que discurrieron los partidos políticos hasta los comicios municipales fueron diversos. Los demócratas se dividieron en dos tendencias en las reuniones públicas celebradas en el Circo de Price los días 11, 18 y 25 de octubre $^{47}$. Por un lado, la de los demócratas puros, que defendían la tesis de la accidentalidad en las formas de gobierno. Nicolás María Rivero, Cristino Martos y Manuel Becerra, sus principales líderes, llegaron después a un entendimiento con progresistas y unionistas plasmado en el manifiesto de conciliación monárquica del 12 de noviembre ${ }^{48}$. Por otro lado, la marcada por quienes apostaban por la República federal como forma de gobierno, capitaneada por Estanislao Figueras, José María Orense y Francisco García López. En la tercera reunión del Circo de Price, esta línea decidió constituir un comité republicano central en Madrid mediante una elección por sufragio universal celebrada los días 8,9 y 10 de noviembre, en la que participaron 13.735 votantes ${ }^{49}$. Dicho comité contaría con treinta integrantes, a razón de tres por cada uno de los diez distritos de Madrid $^{50}$.

46 Diario Oficial de Avisos de Madrid, 12 de noviembre de 1868.

47 Eiras, 2015 [1961]. Sobre los orígenes del partido republicano, véanse también: Castro, 1994 y Peyrou, 2008.

${ }^{48}$ El contenido del manifiesto en: De la Fuente, y Serrano, 2005, pp. 200-203.

49 Hennessy, 2010 [1962], p. 62.

50 La lgualdad, 11 de noviembre de 1868. Véase también la constitución del comité en: Rodríguez Solís, 1893, p. 614. 
La organización del comité republicano central se realizó a partir de los trabajos desarrollados en los comités democráticos de los distritos, que convocaron a sus correligionarios para designar a sus juntas directivas, tratar de asuntos electorales y organizar conferencias públicas sobre la libertad de sufragio, la libertad de cultos y la separación de Iglesia y Estado ${ }^{51}$. A su vez, esos comités se subdividieron en otros a nivel de barrio, encargados de proporcionar a los primeros trabajos útiles para la organización de los comicios municipales ${ }^{52}$. Desde estas células concéntricas del partido republicano se redactaron notas dirigidas a los correligionarios de las diferentes circunscripciones administrativas de Madrid, en las que se reproducían las bases programáticas del grupo referentes a la consagración de derechos y libertades individuales.

Los comités republicanos de los distritos convergieron en su actuación con los clubes democráticos ${ }^{53}$. Las conferencias públicas que se celebraban en sus locales buscaban el adoctrinamiento del «nuevo ciudadano», ayudándole a distinguir entre República federal y República unitaria y enseñándole las bases organizativas del partido. Por su parte, las juventudes adeptas al partido trabajaban en la formación de comisiones para protestar por las limitaciones de edad establecidas por el artículo 1 del decreto del sufragio universal. Su propósito rebajarla hasta los 20 años, objetivo inmediatamente suscrito por el comité central ${ }^{54}$. El apoyo de la población estudiantil se centralizó también a través de la «Asociación propagandista de estudiantes republicanos de Madrid», que ejerció campañas para transmitir lecciones sobre el significado del derecho electoral que los habitantes estaban a punto de estrenar ${ }^{55}$.

La actividad republicana llegó a su punto álgido con la manifestación ciudadana convocada por el comité central el 29 de noviembre. Al acto estaban invitadas las redacciones de los periódicos republicanos, clubes del partido y comités de distritos y barrios. Estos difundieron la convocatoria de manera eficaz entre las bases sociales de cada zona. En cada uno de ellos se adoptó el mismo plan de actuación: fijar un punto de encuentro específico dentro de su demarcación para acudir unidos a la manifestación. Así, los del distrito de Palacio acudieron a la plaza de Santo Domingo tras el Ilamamiento de su presidente Bernardo García, director de La Discusión. Lo mismo hicieron los de Centro desde la plaza de las Descalzas o los de Hospital, encabezados por el concejal Patricio Lozano. Los de Buenavista acudieron con una

51 La Discusión, 12 de noviembre de 1868.

${ }^{52}$ Uno de los primeros en constituirse fue el del barrio de Atocha, que acogía a los electores residentes entre la Plaza de Antón Martín y la Plaza de Atocha. En: La Igualdad, 23 de noviembre de 1868.

53 Gutiérrez, 2001; Pérez Roldán, 2001; Morales, 2002.

${ }^{54}$ La Discusión, 25 de noviembre de 1868.

${ }^{55}$ La lgualdad, 18 de diciembre de 1868. 
bandera en la que se leía «Iglesia libre en el Estado libre»; los de Hospicio otra con el lema «Derecho electoral a los veinte años» y los de Congreso con un estandarte que rezaba "No más reyes, sed libres». La ritualización republicana estalló con interpretaciones de La Marsellesa y cientos de banderas enarboladas por los grupos que cerraban la comitiva.

Gráfico 1. Recorrido de la manifestación ciudadana republicana del 29 de noviembre de 1868 en Madrid

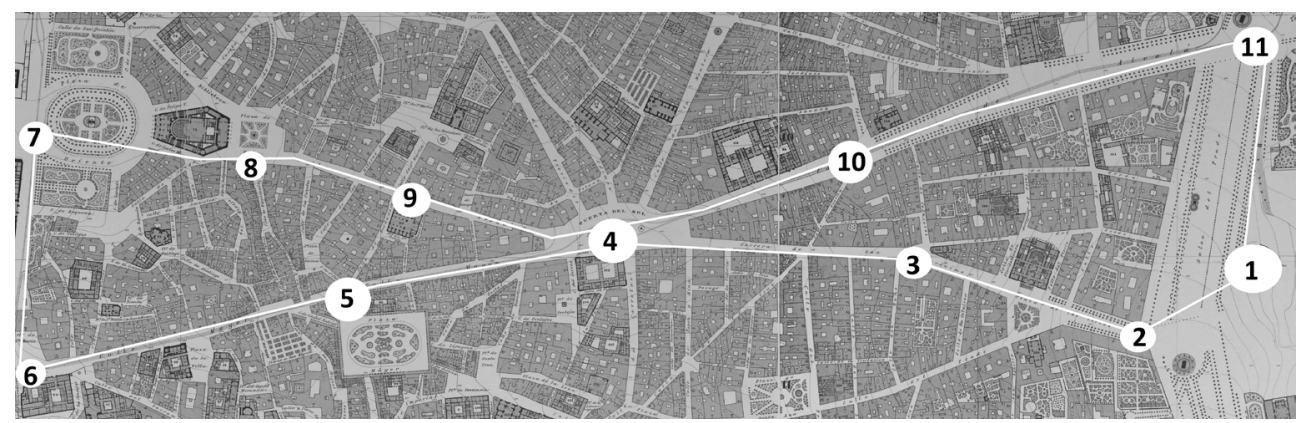

Leyenda: 1 (Monumento a los caídos del dos de Mayo); 2 (Plaza de las Cortes); 3 (Carrera de San Jerónimo); 4 (Puerta del Sol); 5 (Calle Mayor); 6 (Plaza de Armas); 7 (Plaza de Oriente); 8 (Plaza de Prim); 9 (Calle del Arenal); 10 (Calle de Alcalá); 11 (Paseo del Prado).

Teniendo en cuenta lo señalado, cabría haber esperado una preparación meticulosa de la cita electoral municipal por parte de los republicanos. Esta, sin embargo, no llegó a producirse. Aunque no se dejaron de lado compromisos de fiscalización en el desarrollo de las elecciones que tuvieran efectos garantistas sobre los escrutinios, tuvo más importancia el objetivo compartido con los monárquicodemocráticos de hacer del futuro Ayuntamiento la expresión legítima de la opinión pública ${ }^{56}$. Quizás por ello, los comités republicanos se reunieron apenas una semana antes de la elección para la formación de candidaturas. La improvisación con la que actuaron es detectable en el hecho de que algunos ni siquiera llegaron a publicar las listas en prensa y en las renuncias que hicieron ciertos aspirantes a las concejalías, designados más bien por aclamación popular.

El camino seguido por los candidatos monárquico-democráticos presentó ciertas diferencias con respecto a la campaña republicana. La adopción de procedimientos para trasladar el criterio aliancista del 12 de noviembre a los comicios municipales se justificó por la necesidad de conservar los principios proclamados por la Nación en las nuevas instituciones (soberanía nacional, sufragio universal, reconocimiento de libertades asociativas e individuales, inviolabilidad del domicilio y correspondencia, libertad religiosa, de imprenta y de

${ }^{56}$ La Discusión, 9 y 18 de diciembre de 1868. 
enseñanza). La concentración de fuerzas de los partidos favorables a la monarquía y su intervención directa y eficaz en aquella primera lucha electoral se antojaban como elementos decisivos para el porvenir del país y para afianzar las libertades de sus ciudadanos. Aunque en ningún caso se puede atribuir un carácter político a los consistorios que estaban por formarse, la línea de conducta de los monárquicodemocráticos era fundamental para evitar que el embrionario sistema electoral se desnaturalizase en la práctica, bien por un triunfo republicano, bien por una elevada abstención en las urnas.

Desde la óptica monárquico-democrática, las elecciones se entendieron como un basamento previo fundamental para la constitución política del país. En todos los discursos estuvo presente la consideración de los ayuntamientos como cuerpos independientes que emanaban del rechazo de una centralización desaforada durante el ciclo moderado ${ }^{57}$. Esto explica que solo cinco días antes de las elecciones se publicara una circular desde el Ministerio de la Gobernación clamando por la recuperación de su autonomía y prestigio y por evitar, en su formación, coacciones sobre los votantes.

Tomando las anteriores disposiciones como clave de bóveda de su campaña, los monárquico-democráticos centralizaron sus acciones a través de los comités de distrito. Estas células contaban con juntas directivas elegidas por los electores en cada uno de los diez barrios de la circunscripción, funcionando en ellos tres vocalías con carácter representativo. A diferencia de lo que ocurrió con los republicanos, la presentación de candidaturas cerradas se gestionó con eficacia y rapidez. En las reuniones de los comités, los electores de los barrios votaron los nombres que querían ver representados en las listas a partir de una selección previa presentada por las juntas electorales de cada distrito.

Sin embargo, no debe olvidarse que tanto monárquico-democráticos como republicanos entendieron perfectamente que el desarrollo de las elecciones se debía realizar de tal forma que los vecinos votaran inducidos por intereses que les compitieran. Hasta entonces se había considerado el sufragio como un fideicomiso y no como un derecho individual, proporcionado a quienes pudiesen ejercerlo de manera racional ${ }^{58}$. Esto explica que se pusiera énfasis en el carácter social de la capacidad política, considerándose que un determinado vecino solo tendría derecho al voto por pertenecer a una clase que merecía representatividad electoral. De igual modo, reforzaba la visión individualista del voto, es decir, el grado de compatibilidad que cada persona pudiera tener con el sistema político en función de su propiedad y su riqueza, que al mismo tiempo eran criterios fundamentales para garantizar la deferencia de la que podían ser objeto por parte de clases sociales inferiores, su inteligencia y su buen nivel educativo.

\footnotetext{
57 Vilches, 2001; Villena, 2001.

${ }^{58}$ Kahan, 2003.
} 
Ante todo, monárquico-democráticos y republicanos consideraron que los comicios municipales debían corroborar que las prescripciones del decreto del 9 de noviembre serían cumplidas punto por punto. La adopción del sufragio universal aparecía como la respuesta a la demanda de inclusión social de un gran número de habitantes a los que hasta entonces excluidos del ejercicio de la soberanía. Este objetivo explicaría la cordialidad mostrada en ciertos momentos por diarios como La Iberia y La Discusión. El progresista defendió como uno de los aspectos más importantes del envite la preservación absoluta de la neutralidad gubernamental ${ }^{59}$. Por su parte, el republicano celebró que el pueblo tuviera la oportunidad de votar tras tantos años de opresión. Parecía cundir la idea de que el primer ejercicio del sufragio universal debía reflejar la «sacralización de la unidad social» anteriormente perdida ${ }^{60}$, si bien la postura republicana era más agresiva por la reciente declaración monárquica del Gobierno Provisional ${ }^{61}$.

\section{LOS RESULTADOS ELECTORALES}

Un bando publicado por el Ayuntamiento de Madrid el 23 de noviembre de 1868 dio a conocer los procedimientos a seguir para la composición del futuro consistorio. A Madrid le correspondía elegir 47 concejales (cinco por cada distrito salvo en los de Universidad, Audiencia y Congreso, que elegían cuatro). Para facilitar la emisión del sufragio, verificar la identidad de los electores y evitar fraudes, el consistorio acordó que cada barrio constituyera una sección electora ${ }^{62}$. Las elecciones se iniciaron el 18 de diciembre, día en el que todos los vecinos mayores de 25 años estaban convocados para elegir a los presidentes y secretarios escrutadores de las mesas que debían constituirse en los cien barrios de Madrid. Los periódicos abrieron sus ediciones con la lista de los locales donde debía celebrarse ese acto y animaron a los electores a participar de manera extendida, pero reinó la tranquilidad. Así se deduce de lo señalado en La Discusión, donde se destacaba la ausencia de una lucha entre los partidos a la hora de constituir las mesas. Solo en el distrito de Hospital existió «empeño en el triunfo de las candidaturas, y ha tocado llevar la mejor parte al elemento republicano ${ }^{63}$. Por su parte, el diario La Reforma

${ }^{59}$ La lberia, 15 de diciembre de 1868.

60 Se utiliza el término de Rosanvallon para aludir a la instauración del sufragio universal en Francia en 1848, en: Rosanvallon, 1992, pp. 372-390. Sobre esta misma temática aplicada a Francia e Italia, consúltense: Aguilhon, 1992; Fruci, 2008.

${ }^{61}$ Monlleó, 2001; y Ollero, 2006.

62 El bando y las circulares que le siguieron en: AVM, Secretaría, expedientes 4-406-13 y 5-332-8.

${ }^{63}$ La Discusión, 19 de diciembre de 1868. 
rehusó hablar de retraimiento electoral, a diferencia del periódico La Esperanza. Lo único que se había advertido era "la confianza que se inspiraban recíprocamente los partidos» ${ }^{64}$.

La importancia de esa primera votación fue muy reducida. Pocos barrios registraron una participación superior al 20\%. Las votaciones para la elección de los secretarios de las mesas determinaron un panorama muy similar. En las presididas por monárquicos-democráticos, las plazas estuvieron íntegramente representadas por correligionarios del partido con un número de votos muy parejo, lo que mostraba un consenso en la emisión del sufragio. Por el contrario, en las mesas donde se presentaron para la presidencia dos candidatos de distinto signo político, los puestos quedaron repartidos.

Los resultados definitivos de las elecciones reflejan un bajo nivel de participación, siendo 31.491 el número de votantes y 76.095 el de electores (41,38\%). De manera apriorística se podría argumentar que esa abstención habría estado condicionada por posibles deficiencias en la confección de una cartografía electoral que debía diferenciarse por completo de la presentada en años anteriores (un único colegio por distrito). Sin embargo, la relación de locales publicados en la prensa para las votaciones en los cien barrios parece evidenciar que el Ayuntamiento de Madrid buscó, en la medida de lo posible, una coherencia geográfica en cada una de las secciones electorales. Esta organización electoral de la ciudad que primaba la correspondencia de barrios con secciones supuso un modelo a seguir para posteriores citas con las urnas durante la etapa del Sexenio Democrático, pero desapareció en la etapa de la Restauración. Cuando se recuperó el sufragio universal masculino en 1890, el nuevo modelo de cartografía electoral que se impuso fue mucho más imperfecto y fomentó el distanciamiento de ciertos vecindarios con respecto a los colegios donde debían emitir el voto.

La opción de una cartografía electoral deficiente parece descartarse como variable explicativa de la elevada abstención de estos comicios teniendo en cuenta las significativas variaciones que se presentaron a nivel de distrito, dibujándose una movilización del voto más exitosa en los que ofrecían perfiles sociales más acomodados. Centro, Congreso y Audiencia se acercaban a índices de participación cercanos al 50\%, encontrándose en una situación opuesta los de Hospital, Latina e Inclusa, definidos por una concentración más acusada de clases populares.

Un análisis más fino, a nivel de barrio, identifica otros aspectos igualmente destacados. La abstención fue muy elevada en los barrios más baratos del sur del casco antiguo y en los recientemente incorporados a Madrid tras la aprobación del Ensanche como Peñuelas, integrado por jornaleros pobremente remunerados, y Delicias, uno de los principales graneros residenciales para los inmigrantes que

${ }^{64}$ La Reforma, 20 de diciembre de 1868. 
escapaban del hambre rural ${ }^{65}$. El perfil de los anteriores espacios urbanos contrastaba con el de las zonas más céntricas, donde los comités electorales actuaron con mayor intensidad. Los artesanos, comerciantes, funcionarios y profesionales liberales de barrios como Constitución y Concepción en el distrito de Audiencia (junto a la Plaza Mayor y la calle de Toledo), Alcalá en Buenavista (integrando la totalidad de la calle homónima) y Bordadores y Puerta del Sol en Centro conocían los aspectos más básicos de la organización electoral porque habían sido adoctrinados en esos círculos y porque tenían pleno acceso a la información que se publicaba sobre este apartado en la prensa o a través de los bandos y decretos, merced a su elevada alfabetización.

Gráfico 2. Tasas de participación por barrios (elecciones municipales de 1868)

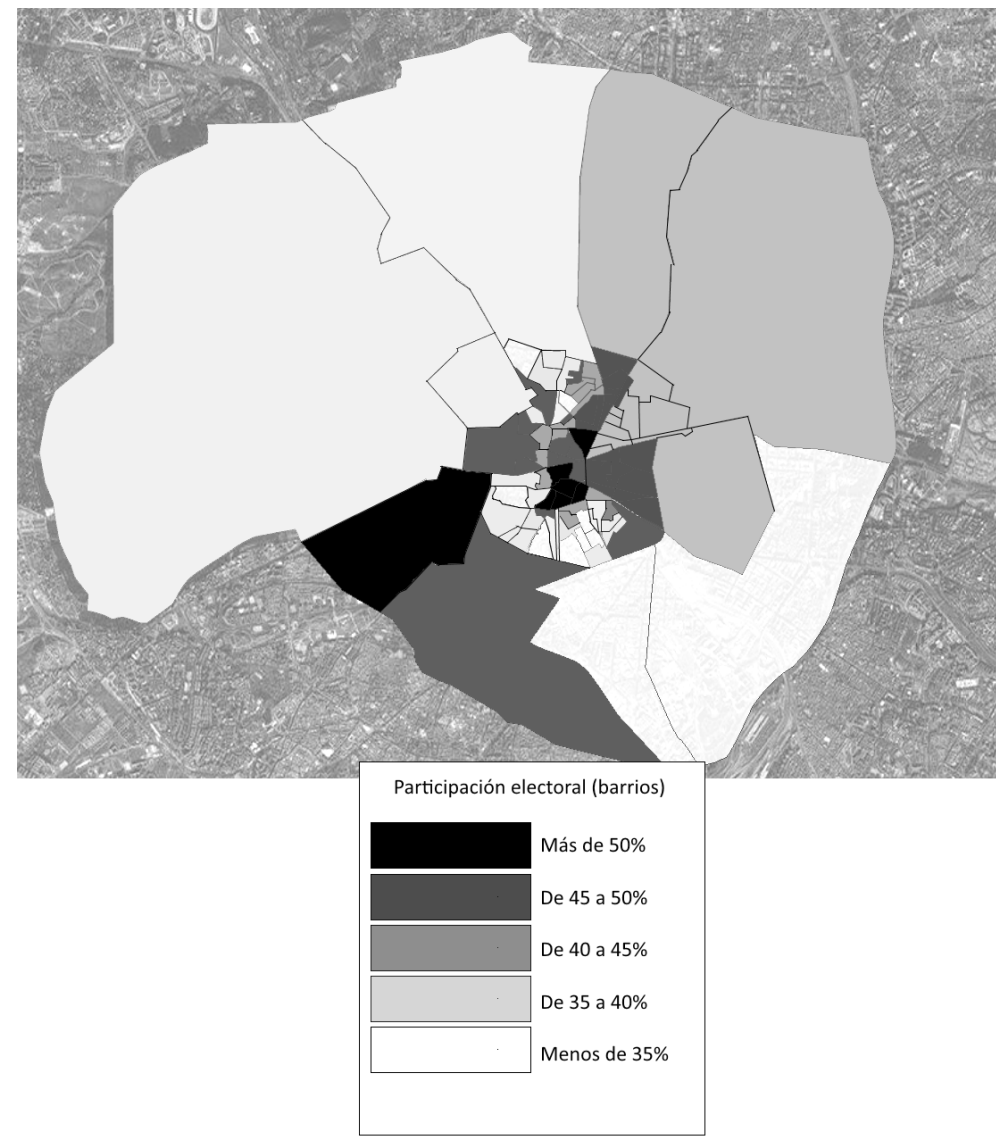

Fuente: Elaboración propia a partir de los datos obtenidos de las actas electorales: AVM, Secretaría, expedientes 4-444-2 a 4-454-1.

${ }^{65}$ Vicente, 2015. 
Sin embargo, las marcadas diferencias entre barrios y distritos también respondieron a la falta de previsión técnica del Ayuntamiento en el reparto de las cédulas talonarias de vecindad que certificaban el derecho al voto. La imposibilidad de llevar a cabo la realización de un nuevo padrón de habitantes por falta de tiempo provocó que la distribución de los documentos identificativos de los electores se realizara conforme al redactado el 1 de enero de 1868. Los habitantes que no figuraban en él tenían la responsabilidad de pedir a los alcaldes de barrio las cédulas si en aquella fecha se encontraban fuera de Madrid o si se habían mudado, acudiendo en última instancia a identificarse a las propias oficinas del consistorio ${ }^{66}$. No se estaba valorando con la suficiente relevancia ni el contingente de electores que por su anterior condición de exiliados políticos no habían regresado a la capital hasta los meses de octubre y noviembre ni el movimiento natural de la población, que dejaba obsoleta una parte significativa de la información recolectada en el señalado padrón municipal.

Sin embargo, el principal problema para articular el derecho electoral tenía que ver con la intensa movilidad residencial de Madrid. En una ciudad donde más del $90 \%$ de la población vivía de alquiler, el asentamiento de una familia en una vivienda era temporal. La perspectiva actual, que tiende a considerar el cambio de residencia como una actividad disruptiva desde un punto de vista social y emocional, no se presentaba en una época en que era un acontecimiento cotidiano, que sobrevenía en cualquier momento por el desempleo o la muerte del cabeza de familia. Para los inquilinos más humildes, el coste social del desplazamiento era reducido. Disponían de pocos enseres que trasladar y no establecían un compromiso con la vivienda inicialmente habitada, con lo que convertían sus traslados en estrategias dependientes de las necesidades económicas del momento.

Los repartos de cédulas talonarias realizados hasta el 6 de diciembre evidenciaron el problema y llevaron a Nicolás María Rivero a fijar disposiciones para amplificar el derecho electoral. Rivero admitió que a muchos habitantes no les había llegado el documento por haber "adquirido domicilio fuera del barrio en que habitaban a principios del año" y por haber "estado en confinamiento político ${ }^{67}$. En consecuencia, instó a los primeros a presentarse entre los días 7 y 16 de diciembre en la sección de Estadística del Ayuntamiento para solicitar la cédula, con el único requisito de indicar su domicilio anterior. En cuanto a los segundos, se les permitía reclamar el documento por escrito en idéntico plazo y acompañando informes comprobantes de su situación. La circular incluía un tercer apartado que concernía a quienes no se les había entregado la cédula por omisiones de los alcaldes de barrio o por no encontrarse en sus viviendas

${ }^{66}$ Diario Oficial de Avisos de Madrid, 1 de diciembre de 1868.

67 AVM, Secretaría, expediente 4-406-20. 
por motivos laborales en el momento del reparto, abriéndose para ellos un nuevo plazo para presentar reclamaciones por escrito. Los datos de las actas confirman, sin embargo, la escasa resonancia de estas medidas. Los repartos de cédulas fueron más efectivos en los distritos que manifestaron una mayor animación, como Audiencia, Centro y Congreso. Por el contrario, en Hospital, Latina e Inclusa los porcentajes de electores sin cédulas fluctuaban entre un 35 y un $40 \%$.

En cierta manera, lo que evidencian los datos anteriores es el insuficiente empeño que los organizadores del sufragio universal pusieron a la hora de conceder a los habitantes todo tipo de información relativa a su inscripción en las listas electorales. Esta fue, por ejemplo, una prioridad indiscutible en el caso francés, coincidiendo con la aprobación del extendido derecho político mediante decreto de 5 de marzo de 1848. En París, las gestiones de inscripción de los nuevos electores se realizaron con carácter diario y los horarios de apertura de las oficinas municipales se prolongaron hasta la madrugada, con el fin de evitar que las diferencias entre los habitantes en lo que respecta a sus condiciones sociales se convirtieran en obstáculos para el ejercicio de la ciudadanía política ${ }^{68}$. A través de la puesta en marcha de mecanismos empíricos y pragmáticos, se pudo crear un compacto cuerpo electoral de masas.

En el caso de España en general y de Madrid en particular, parece evidente que la creación de las listas electorales fue un proceso que, por su complejidad, presentó inicialmente fallas importantes que se fueron tapando progresivamente en comicios posteriores. La puesta en marcha del sufragio universal implicaba el cumplimiento de un enorme número de tareas burocráticas que dejaron anticuado el cuerpo administrativo encargado de los preparativos electorales en años precedentes. Se hizo necesaria, por ejemplo, la contratación de un importante número de empleados municipales suplementarios sobre quienes recayó el cometido de repartir las cédulas de vecindad. Aun cumpliendo con una tarea fundamental, lo cierto es que esa técnica de registro de electores a domicilio adolecía de serias limitaciones. Los encargados de la repartición de cédulas apenas se tomaron la molestia de averiguar el cambio de habitación de los vecinos comprendidos en el padrón del 1 de enero de 1868 y solo cumplían con sus cometidos de día, con lo que no encontraban en sus casas a los electores que se hayaban ocupados laboralmente en ese momento ${ }^{69}$.

68 Villette, 2013, pp. 124-127.

69 Estas deficiencias fueron señaladas a renglón seguido de la cita electoral municipal en una carta dirigida al Ayuntamiento de Madrid por parte de la Junta Provincial Electoral. En: AVM, Secretaría, expediente 5-332-8. 
Gráfico 3. Cédulas de vecindad no entregadas ni reclamadas por distritos

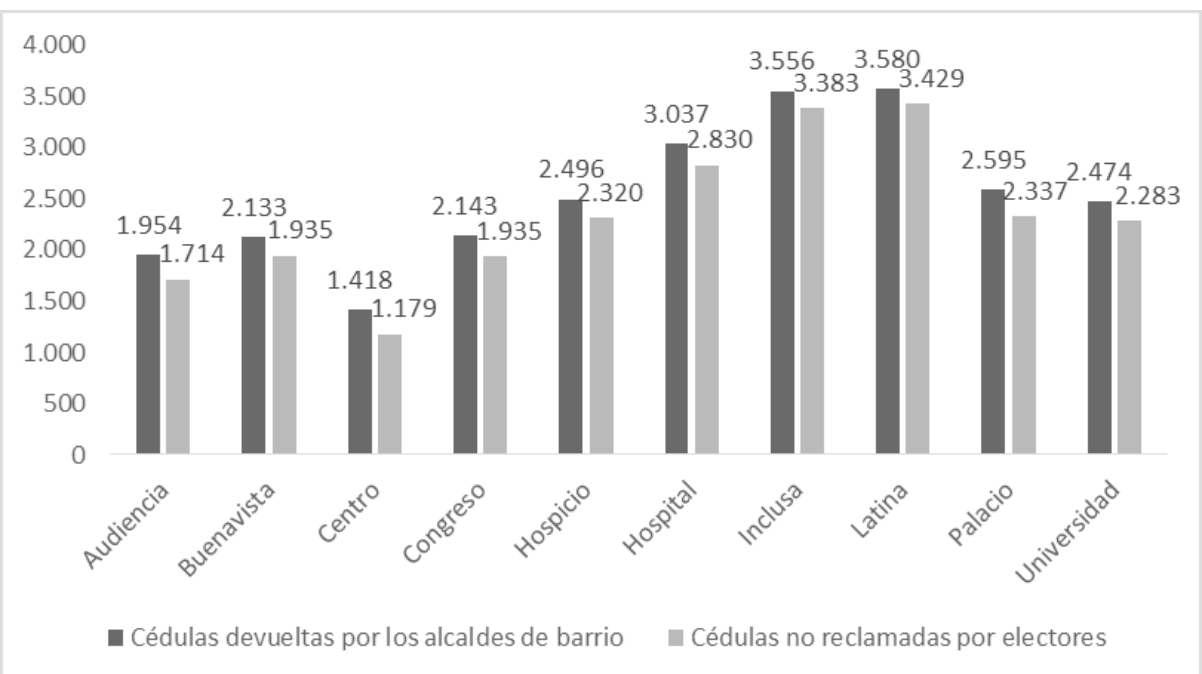

Fuente: Elaboración propia a partir de las actas de escrutinio y libros talonarios de las elecciones municipales de 1868. Fuente: AVM, Secretaría, expedientes 4-444-2 a 4-454-1.

Gráfico 4. Participación electoral de los vecinos que contaban con cédulas talonarias de vecindad por distritos

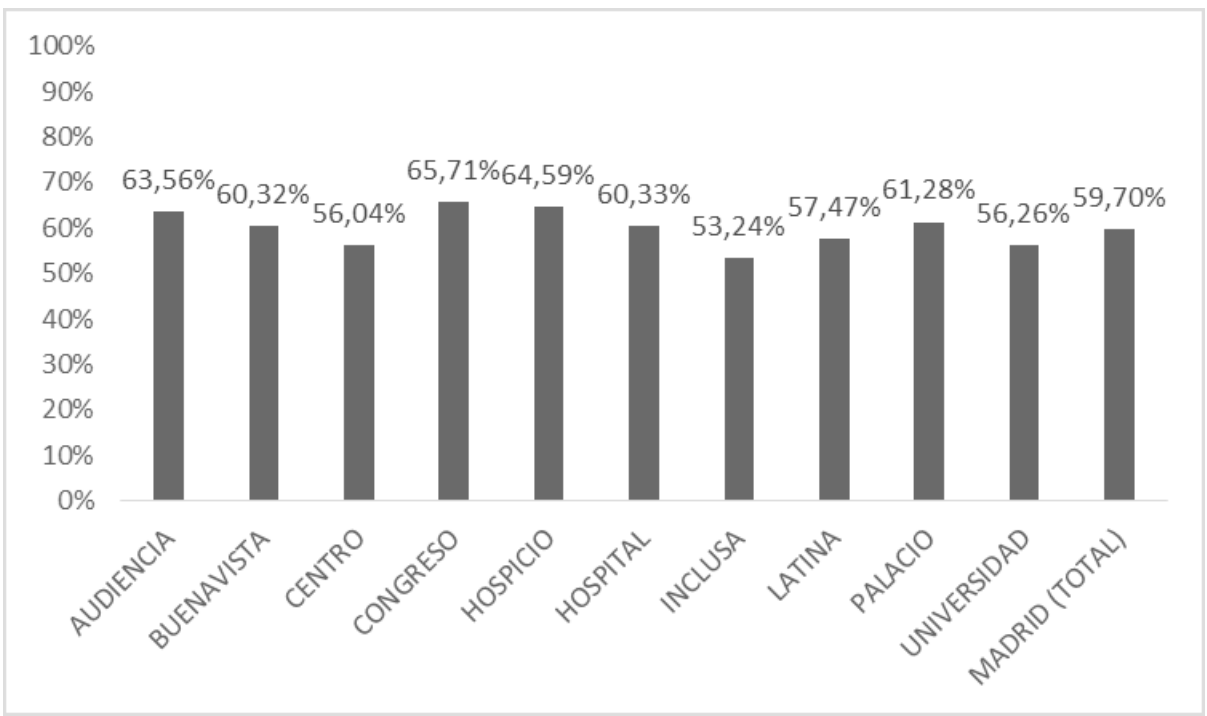

Leyenda: Los porcentajes expresados en esta tabla resultan de haber restado al número total de electores la cifra de cédulas talonarias de vecindad que quedaron sin reclamar en las oficinas del Ayuntamiento de Madrid. Elaboración propia a partir de: AVM, Secretaría, expedientes 4-444-2 a 4-454-1. 
No obstante, las debilidades organizativas del nuevo derecho electoral mostradas en estos comicios sirvieron como ejemplo para los legislativos de enero. En esta ocasión, las cédulas se distribuyeron en función de lo estipulado en el último padrón de habitantes formado a finales de 1868 y los ayuntamientos nombraron para su reparto tantas comisiones como secciones tuviera cada distrito, apuntaladas además con la presencia del alcalde de barrio y de cuatro electores de cada colegio. Los integrantes de esas comisiones repartieron las cédulas prácticamente hasta el mismo día en que se votaron las mesas electorales. Las sobrantes quedaron en las oficinas municipales, pero se determinó que todos aquellos vecinos que no estuvieran en posesión de las mismas tendrían la oportunidad de reclamarlas acreditando su personalidad mediante una fórmula novedosa. Su derecho quedaría probado siempre y cuando fueran reconocidos por dos vecinos del barrio en el que aparecían domiciliados. Además, no se perdió de vista el hecho de que muchos electores habían extraviado en la cita electoral de diciembre las cédulas una vez recibidas. Para subsanar este problema, se tomó la decisión de conceder el derecho de reclamarlas por segunda y hasta por tercera $v z^{70}$. La salida de una sociedad no igualitaria desde un punto de vista político exigía, en definitiva, una fase previa de aprendizaje que fuera solucionando las inevitables confusiones iniciales del período de funcionamiento del sufragio universal masculino.

Otro aspecto que debe valorarse a la hora de analizar la participación en estos comicios tiene que ver con el hecho de que las votaciones no se realizaban en un solo día, sino en tres consecutivos, lo que teóricamente daba más facilidades a la población para la emisión del sufragio adaptándolo a sus quehaceres profesionales. Coincidiendo las tres jornadas con sábado, domingo y lunes $(19,20$ y 21 de diciembre), la asistencia a los colegios fluctuó enormemente entre los dos primeros días y el tercero. No se encuentran completos los datos electorales por días, resultando irrealizable la desagregación de votos en los distritos de Centro, Hospicio y Congreso. Sin embargo, la información del resto de distritos sí se ha conservado y resulta interesante para realizar aproximaciones cualitativas. En los distritos populares (Hospital, Latina e Inclusa), el voto aparece condicionado por la actividad laboral y por representar el domingo el único día de descanso semanal de la mayoría de cabezas de familia. La situación era distinta en otras zonas más acomodadas como Audiencia y Buenavista, donde los índices de participación se incrementaban sustancialmente en sábado y lunes.

70 Véanse algunas de las soluciones orientadas a la corrección de las deficiencias organizativas del sistema electoral en: Gaceta de Madrid, 30 de diciembre de 1868 y 7 de enero de 1869. 
Ejemplificador en este sentido es el caso del distrito de Hospital. Las cuatro concejalías que los republicanos lograron en esta demarcación fueron deudoras de las votaciones presentadas por barrios que no habían configurado un perfil político específico en épocas pretéritas y por zonas donde la condición socio-profesional del vecindario había restringido las proporciones de electores durante el período de funcionamiento del sufragio censitario. El carácter decisivo que estos enclaves tuvieron para que salieran triunfantes las concejalías de Pedro Pallarés, Estanislao Figueras, Diego López Santiso y Patricio Lozano (quedando en manos de los monárquico-democráticos la minoría de Julián Viñas) se explica atendiendo a los amplios apoyos obtenidos por la candidatura el día 20, en el que los trabajadores manuales de esos puntos acudieron en masa a las urnas para ejercer el derecho al sufragio.

Gráfico 5. Participación por distritos en las elecciones municipales de 1868 en Madrid en función de la jornada de votación

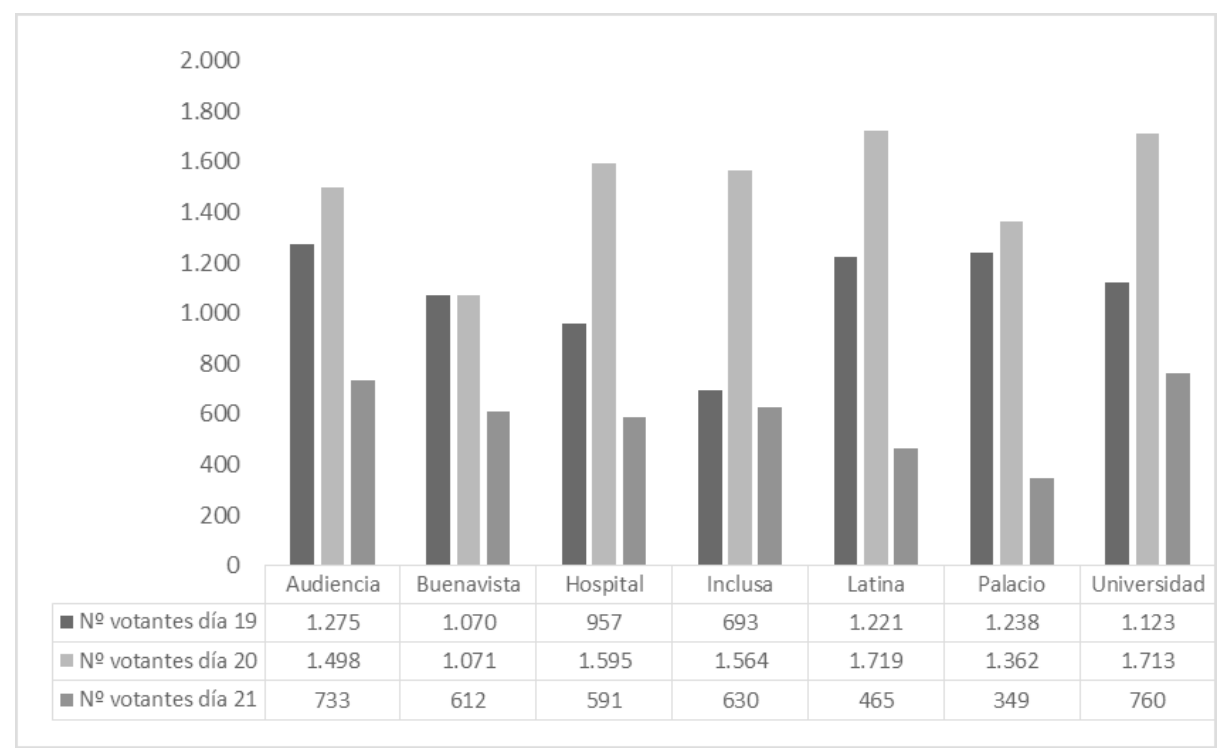

Fuente: AVM, Secretaría, expedientes 4-444-2 (Palacio), 4-445-1 (Universidad), 4-448 (Buenavista), 4-450-1 (Hospital), 4-451-1 (Inclusa), 4-452-1 y 4-453-1 (Latina) y 4-454-1 (Audiencia). 
Gráfico 6. Resultados electorales por jornada de votación en Hospital

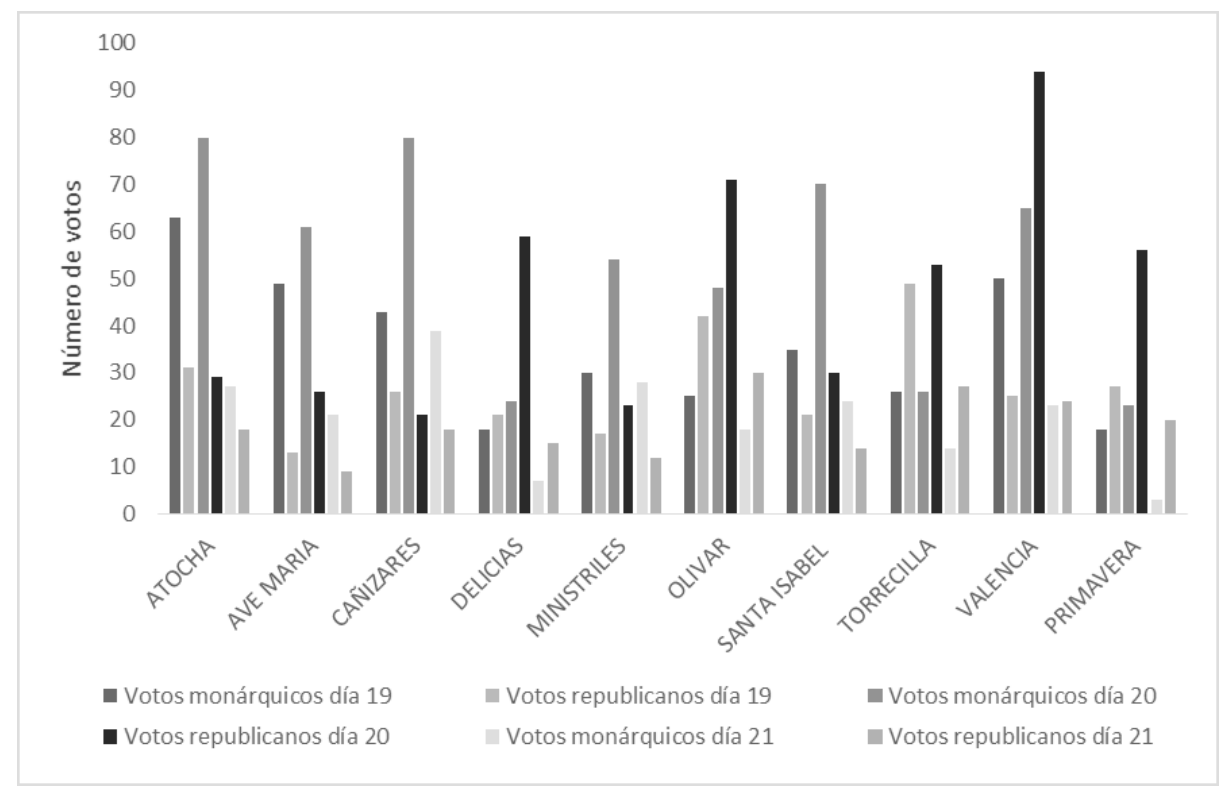

Fuente: AVM, Secretaría, expediente 4-450-1.

El éxito republicano en Hospital se basó tanto en el protagonismo que los candidatos jugaban en la vida cotidiana de sus barrios como en la actividad propagandística desarrollada en comités y clubes y en el prestigio social acumulado en los meses que siguieron a la Septembrina. Dejando a un lado a Estanislao Figueras, parte activa del movimiento revolucionario y miembro de la Junta Revolucionaria interina, no resulta extraño que fuera Diego López Santiso quien cosechara un mayor número de votos, teniendo en cuenta la actividad comercial que ejercía en la zona como propietario de un negocio de ultramarinos en la calle de Atocha, el papel que desempeñaba como activista del partido en el distrito (desde el comité electoral, desde la antigua Junta Revolucionaria de Antón Martín y desde los clubes republicanos que se acababan de fundar en esas semanas) y el prestigio que había obtenido como regidor del consistorio popular formado el 9 de octubre. Similar era el caso del abogado Patricio Lozano, también concejal antes de la votación y uno de los militantes de más amplio recorrido del Partido Demócrata desde su fundación. Pallarés, por su parte, era profesor de equitación y uno de los grandes agitadores del partido desde la creación de la Junta Revolucionaria de Antón Martín. Desde ella se puso en contacto con los Voluntarios de la Libertad de esta demarcación y con sus habitantes para conocer sus convicciones días después del triunfo de la revolución. El único miembro de la candidatura que quedó sin concejalía fue José Guisasola, médico y propietario del periódico republicano La lgualdad $^{11}$.

\footnotetext{
${ }^{71}$ La Iberia, 15 de octubre de 1868.
} 
Gráfico 7. Tendencia del voto por candidaturas en los barrios del distrito de Hospital

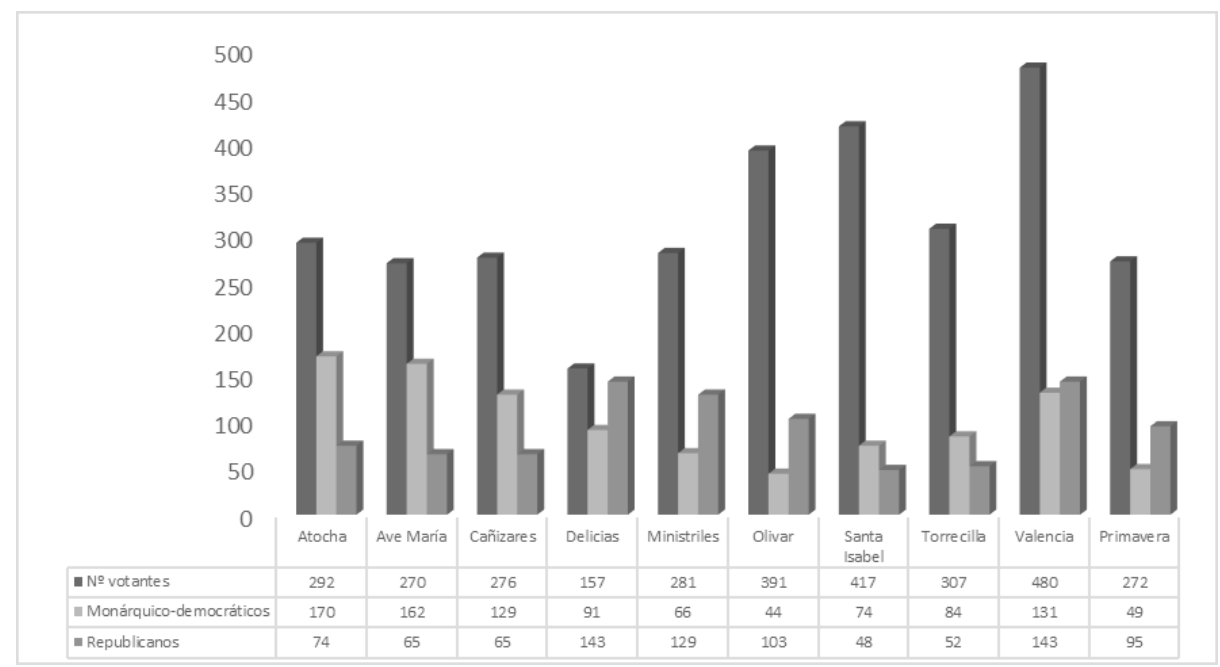

Leyenda: Tanto en esta tabla como en las que siguen se consigna en las columnas referidas a las candidaturas monárquico-democrática y republicana la cifra de votos obtenida por el integrante de las mismas más apoyado en las urnas (Julián Viñas en la primera y Diego López Santiso en la segunda).

En algunos estudios se ha señalado que el quinto y último concejal republicano que salió de las urnas en aquellas jornadas fue Camilo Laorga por Inclusa. No obstante, Laorga nunca llegó a figurar en otra candidatura distinta a la monárquicodemocrática ${ }^{72}$. En los meses anteriores había ejercido como miembro de la Junta Superior Revolucionaria de Madrid, entendiendo en los asuntos relacionados con el gobierno interior de la ciudad. Destacó por ser uno de los grandes industriales del distrito. Llegado a la capital en 1850, fue ascendiendo en la escala social desde los primeros trabajos realizados como carpintero. Fue a partir de 1860 cuando comenzó a hacerse un nombre en la industria especializándose en la construcción de mesas de billar ${ }^{73}$. Pero al margen de por su actividad industrial, Laorga destacó por su intervención en la vida pública del distrito. Durante la epidemia de cólera de 1865 puso al servicio de la Junta de Socorros allí formada su local, donde los vecinos acudían diariamente a por medicamentos ${ }^{74}$. También preservó el orden público en los días que siguieron a la revolución actuando como primer comandante del segundo batallón de Voluntarios de la Libertad. Estos precedentes le concedieron un apoyo muy significativo, si bien sus porcentajes de voto más altos se lograron en el barrio de Peñuelas, donde ejercía como principal figura de la comunidad barrial.

72 La Época, 17 de diciembre de 1868.

73 Diccionario Biográfico de Comerciantes, Industriales y Agricultores, Madrid, Escuela Tipográfica del Hospicio, 1891, pp. 59-60.

${ }^{74}$ La Discusión, 15 de octubre de 1865. 
Gráfico 8. Tendencia de voto por candidaturas en los barrios del distrito de Inclusa

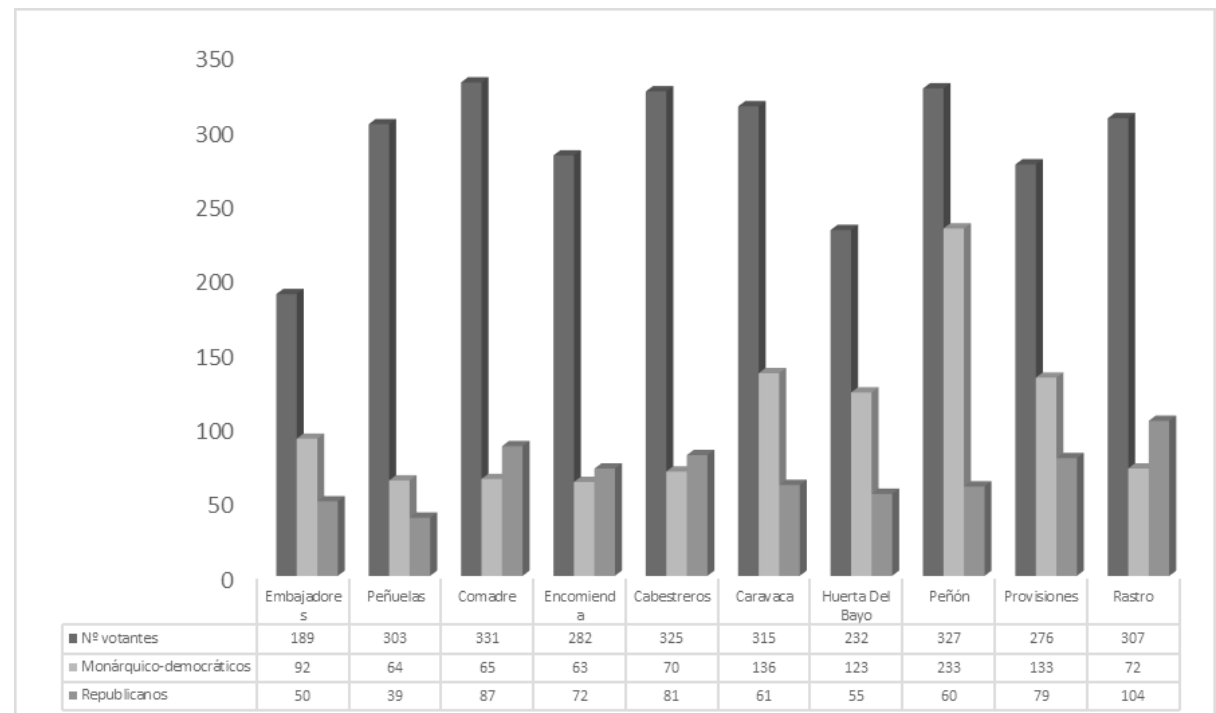

Leyenda: Las cifras de votos de la lista monárquica-democrática se corresponden con los obtenidos por Juan Fernández Albert y las de la republicana con los de José Antonio Cosías. AVM, Secretaría, 4-451-1.

En cuanto al resto de candidatos monárquico-democráticos por Inclusa, el más votado fue Joaquín Fernández Albert, aunque a la hora de valorar su apoyo cabe tener en cuenta tanto el hecho de que su nombre ya había aparecido en las urnas improvisadas en los barrios del distrito a principios de octubre para elegir a los titulares de la Junta Superior Revolucionaria ${ }^{75}$. Manuel Bravo aparecía a continuación, siendo una figura muy conocida en el vecindario tras haber actuado como teniente de alcalde del distrito en años anteriores y haber dirigido la Junta de Socorros de los Amigos de los Pobres a finales de 1865 para combatir una epidemia de cólera particularmente dramática en esta zona ${ }^{76}$. Si bien de Leandro Marichalar no se tienen noticias en el distrito antes de los episodios revolucionarios, de Román Ortiz es posible constatar su actividad como uno de los progresistas de más largo recorrido en sus barrios. Había formado parte de sus juntas electorales para la designación de candidatos a las concejalías en los comicios de 1860, ejerciendo al mismo tiempo el cargo de subdelegado de Veterinaria.

El quinto concejal republicano salió, en realidad, del distrito de Universidad, donde se acudía con una candidatura elegida de antemano en el comité. La formaban Antonio Vallés, Santiago Gutiérrez, Juan Altolaguirre y Pedro Carrasco, siendo los dos primeros quienes obtuvieron un mayor número de votos. Aunque

75 La Correspondencia de España, 3 de octubre de 1868.

76 La Soberanía Nacional, 24 de octubre de 1865. 
Vallés ha sido incluido en otros estudios como integrante de la candidatura monárquico-democrática, los datos recabados en prensa nos llevan a situarlo en las republicanas. Santiago Gutiérrez, por su parte, se había distinguido en los barrios del casco antiguo de esta demarcación como un comerciante de renombre, gracias al establecimiento que regentaba en la plazuela de San Ildefonso, y buscaba renovar la concejalía provisional que le avalaba desde la formación del Ayuntamiento Popular de Madrid.

Los resultados fueron los más ajustados de toda la ciudad. Poco más de cien votos mediaron entre el primer concejal electo, José Rodríguez Villabrille, y el cuarto, Ruperto Fernández de las Cuevas, ambos de la lista monárquico-democrática junto a Gregorio de las Pozas y Manuel Salvador. El voto de los trabajadores manuales parecía asegurado con la presencia del primero, propietario de un almacén de camas en la calle de Fuencarral y vicepresidente del Fomento de las Artes, una sociedad de artesanos que buscaba su instrucción y bienestar ${ }^{77}$. A Gregorio de las Pozas le avalaba su condición de promotor de una barriada situada entre el portillo de San Bernardino y la puerta del Conde Duque ${ }^{78}$. Fernández de las Cuevas se había significado desde la revolución de julio de 1854, siendo uno de los que concurrió a la llamada Declaración de los treinta, donde se fijaron los puntos fundamentales del Partido Demócrata. Antes de transigir con la fórmula monárquica fue miembro de la primera Junta Revolucionaria, desde la que pasó a formar parte del Ayuntamiento Popular ${ }^{79}$.

Los tres sacaron sus concejalías sin sobresaltos, pero no así Manuel Salvador, antiguo director del Banco de Isabel II y propietario de fincas en el casco antiguo ${ }^{80}$. Vallés se hizo con ese puesto gracias a los votos logrados en barrios como Pez, Corredera, Dos de Mayo, Daoiz y Colón, situados en pleno centro, pero tendentes a la concentración de clases populares, y en el de Campo de Guardias, en el Ensanche y exento de articulación política. Su éxito bien podía responder a la actividad ejercida como médico numerario de la Junta de Beneficencia Municipal de Madrid en los primeros embates de la epidemia de cólera de 1865, iniciada en los alrededores del Portillo de San Bernardino y extendida después por la zona norte de la ciudad. El recuerdo del socorro médico proporcionado durante los peores momentos de la enfermedad y la actividad que mostró en el distrito desde finales de septiembre de 1868 al servicio de la causa revolucionaria le sirvieron para recibir el voto de casi un $50 \%$ de los electores que acudieron a las urnas en los barrios anteriormente señalados.

\footnotetext{
77 Viñao, 1990.

78 Sobre la actividad inmobiliaria de esta figura, véase: Díez de Baldeón, 1993.

79 Los Diputados pintados por sus hechos..., op. cit., pp. 153-154.

80 Según los datos obtenidos de: Rodríguez Chumillas, 2002, pp. 150-152.
} 
Gráfico 9. Tendencia del voto por candidaturas en el distrito de Universidad

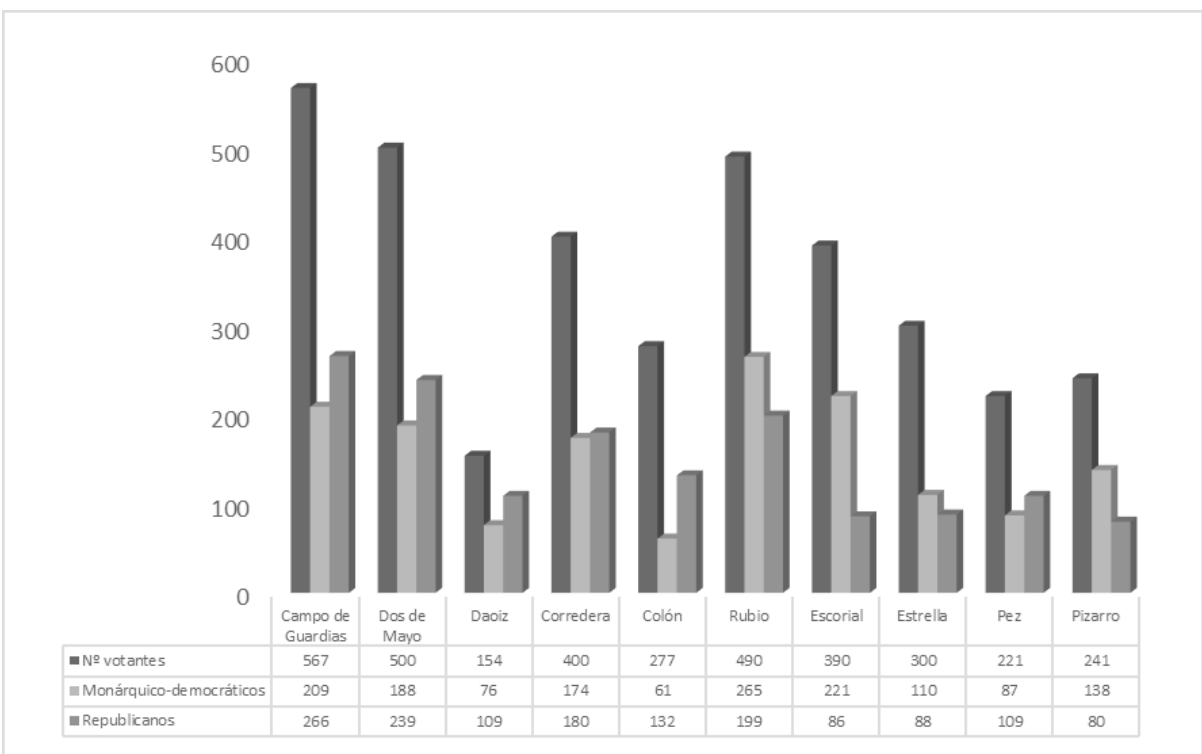

Leyenda: Los votos monárquico-democráticos se corresponden con los obtenidos por José Rodríguez Villabrille y los republicanos, con los de Antonio Vallés. AVM, Secretaría, expediente 4-445-1.

El análisis del voto republicano en el resto de distritos se aparta por completo de lo mostrado en Hospital y Universidad. Desde las tribunas de prensa del partido se admitió que la posición de los monárquico-democráticos era superior por contar con una importante red de apoyos sociales y una gran ascendencia moral deudora de su identificación como artífices de la Revolución. Para Hennessy, una de las posibles causas que explicaría su escaso número de votos en Madrid tendría que ver con el duro golpe que para el partido supuso la limitación del voto a los cabezas de familia mayores de 25 años $^{81}$. Para un grupo que se definía como abanderado de la juventud, esa normativa suponía un contratiempo. En consecuencia, no debe extrañar que tras los comicios la prensa republicana justificara la derrota por las limitaciones etarias en el ejercicio del sufragio.

Fernando Garrido y Elías Reclús mostraron ya en esa época una postura más crítica que la de los rotativos republicanos. Cuando el primero tuvo noticia del éxito logrado en diferentes capitales de provincia, señaló que el partido no se había presentado en Madrid con el mismo grado de cohesión que en Valencia, Zaragoza, Sevilla o Barcelona ${ }^{82}$. La situación de la capital española llamaba la

81 Hennessy, 2010 [1962], pág. 65.

82 Los resultados de las elecciones municipales confirmaron la influencia de los republicanos en el área mediterránea, triunfando en diversas zonas de Cataluña, Valencia y Andalucía y obteniendo la alcaldía en veintiuna capitales de provincia (Alicante, Barcelona, Cádiz, Castellón, 
atención si se comparaba con la catalana, donde hubo una movilización política republicana muy intensa desde un primer momento. Janué aludió a un mayor interés de los republicanos federales barceloneses por integrarse en las nuevas formas de participación política que brindaba el sufragio universal, como se demostró con la creación de nuevos medios de prensa con características propias de los partidos de masas y con los intentos desarrollados para controlar la militancia a partir de los comités, los clubes y los círculos, con numerosos mítines y conferencias públicas. Esa movilización no fue tan amplia en el caso de Madrid, lo que unido a su caracterización como ciudad oficial explicaba, en palabras de Garrido, una derrota que debía servir de ejemplo para las siguientes elecciones legislativas ${ }^{83}$.

Reclús, por su parte, significó la actitud evangélica de los republicanos madrileños y su falta de interés en esta lucha electoral, determinada por la convicción de que el ambiente de la capital no era lo suficientemente favorable a la nueva fórmula de la República federal. Este autor también comparó la actitud de los republicanos catalanes con la de los madrileños, mucho menos vehementes a la hora de combatir la declaración monárquica del Gobierno Provisional. A todo esto había que unir el compromiso político que tenían los candidatos a las concejalías barcelonesas con el programa del partido y la notable sensibilidad y preocupación que ofrecían por los temas sociales del mundo urbano, cuestiones ya estudiadas por Janué ${ }^{4}$.

En lo que se refiere a las elecciones municipales, el Comité de Madrid parece ignorar o despreciar, considerándolo sin importancia, el escrutinio. Ni un llamamiento a los electores, ni una asamblea, ni un pasquín. Los diarios del partido - muy mal redactados - se ocupaban de cosas ajenas a las elecciones, mientras que Rivero y sus amigos republicanos-monárquicos iban personalmente de tienda en tienda y hacían propaganda a las mujeres del mercado para influir en sus maridos. ¿Qué ha sucedido? Que más de la mitad de los electores se han abstenido de tomar parte en la contienda; que los de los veinticinco mil republicanos que hicieron la manifestación de Madrid y de los trece mil que se reunieron en el Circo Price, tan sólo seis mil han depositado su voto en las urnas ${ }^{85}$.

Córdoba, Huelva, Jaén, La Coruña, Lleida, Málaga, Murcia, Orense, Huesca, Santander, Sevilla, Tarragona, Teruel, Toledo, Valencia, Valladolid y Zaragoza). En: Esteban, 1994, p. 98. Entre los estudios locales que se abordan en algunos aspectos de la nueva competencia electoral destacan: Gil Novales, 1980; Heras, 1981; Gutiérrez, 1987, pp. 387-391; Herrán, 1986; Serrano, 1992; Villanueva, 1993; Monlleó, 1996; Arias, 2010.

\footnotetext{
83 La Discusión, 22 y 23 de diciembre de 1868.

84 Janué, 2002, pp. 259-289.

85 Reclús, 2007, p. 169.
} 
Las declaraciones de Garrido y Reclús eran certeras. Incluso Latina, a priori un distrito favorable para la causa republicana por el perfil social de sus habitantes, dejó un porcentaje de voto relativamente bajo. En esos resultados influyó decisivamente la presencia de una figura clave para la creación del clima revolucionario desde las columnas de El Imparcial como Eduardo Gasset y Artime ${ }^{86}$. Le acompañaban Manuel Prieto, catedrático veterinario de primera clase comprometido con la necesidad de construir viviendas higiénicas para la clase obrera, Juan Antonio Sánchez Blanco, Alfonso Sánchez Talavera (propietario y comandante primero del segundo batallón del distrito en las filas de los Voluntarios de la Libertad) y el comerciante Julián Sevilla.

Gráfico 10. Tendencia de voto por candidaturas en los barrios del distrito de Latina

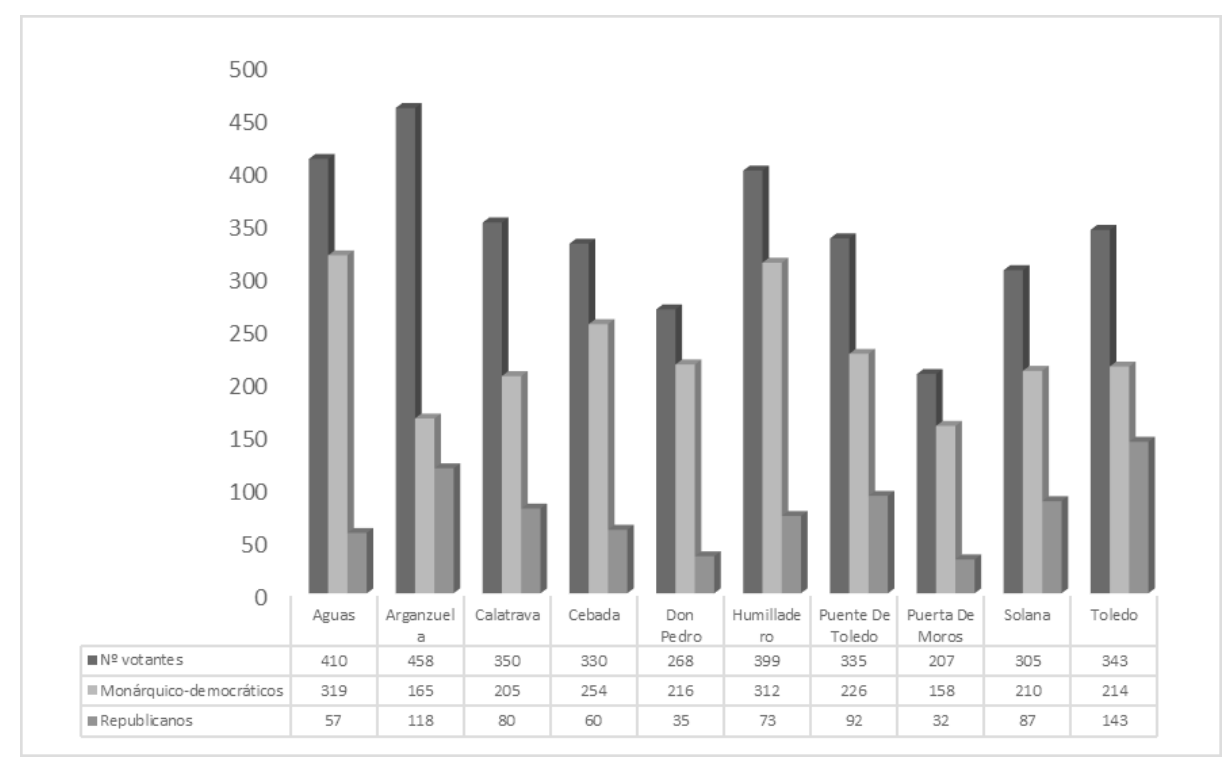

Leyenda: Los votos monárquico-democráticos se corresponden con los recibidos por Eduardo Gasset y Artime y los republicanos, con los de Francisco Quelle. AVM, Secretaría, 4-452 y 4-453.

Sin embargo, el caso extremo en términos de voto republicano lo representaba el distrito de Buenavista. El candidato más votado del partido, Francisco Merino Gallo, tan solo acumuló 156 votos frente a los 1.848 de Ángel Fernández de los Ríos, primer nombre de la lista monárquico-democrática. Aunque su derrota era muy previsible en barrios poco proclives a planteamientos políticos radicales por la condición social de sus habitantes (Alcalá, Belén y Almirante), otros podían considerarse más factibles para sus intereses, ya fuera por su carácter comercial

86 Sánchez Illán, 1996. 
(Montera, Reina) o por una concentración de clases populares nada desdeñable (Plaza de Toros). En ambos casos, las posibilidades de los republicanos quedaron limitadas por la circulación de diferentes candidaturas de conciliación monárquica. De esta manera, mientras en algunos barrios triunfaba la elegida en la junta electoral, formada por Ángel Fernández de los Ríos, Santiago Olózaga, Casimiro Gil, José García Cachena y Felipe Ibarra; en otros vencían listas alternativas que incluían al arquitecto Francisco de Cubas, el periodista Tomás Capdepón, el propietario conde de la Patilla y Antonio Aguirre ${ }^{87}$.

Gráfico 11. Tendencia de voto por candidaturas en los barrios del distrito de Buenavista

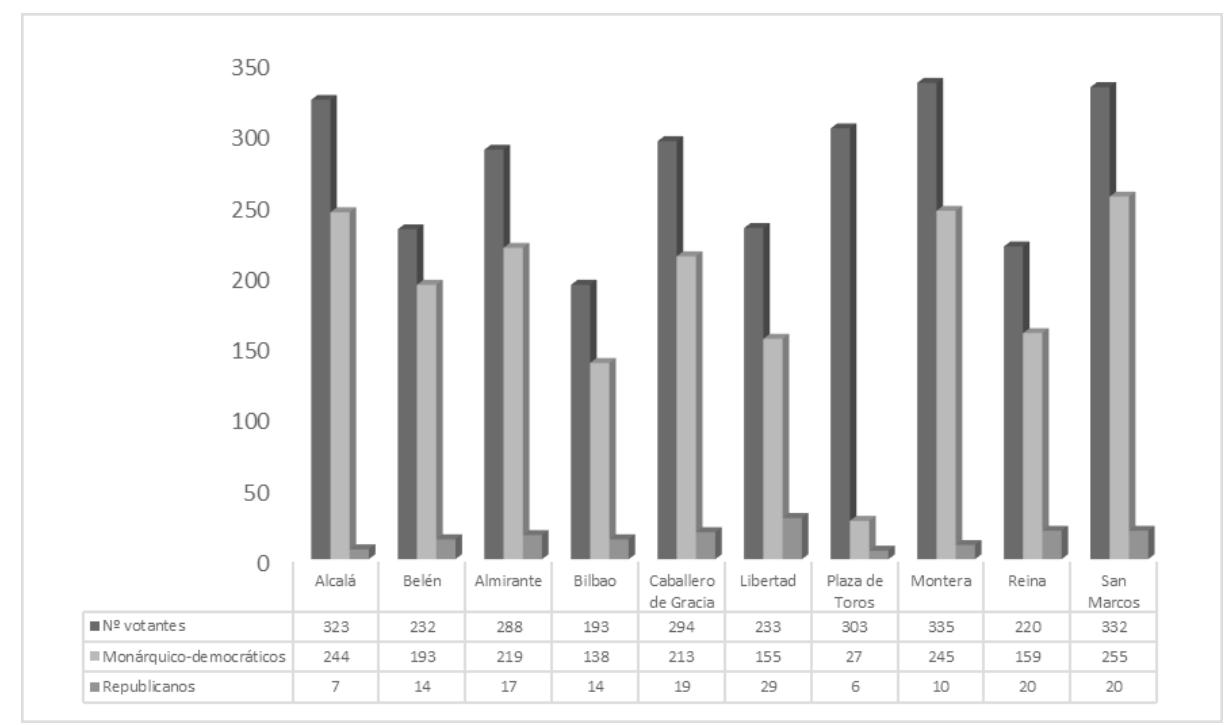

Leyenda: Los votos monárquico-democráticos se corresponden con los obtenidos por Ángel Fernández de los Ríos y los republicanos, con los de Francisco Merino Gallo. AVM, Secretaría, 4-448.

Lo anteriormente señalado en Buenavista adquiere validez en los distritos de Congreso, Palacio y Audiencia. El primero fue el que más claramente mostró la dirección que en esos días asumió la voluntad popular de los madrileños. Nicolás

87 De los integrantes de la candidatura oficial, José García Cachena (comerciante) y Santiago Olózaga (farmacéutico) figuraron como vicepresidente y vocal de la Junta Revolucionaria interina del distrito. Felipe Ibarra, propietario de un negocio en la calle de la Montera, y Casimiro Gil, cerrajero en la calle de las Salesas, participaron en las reuniones del comité electoral elegido en noviembre al igual que Ángel Fernández de los Ríos. El elevado número de votos cosechado por el conde de la Patilla y Tomás Capdepón pudo representar su confirmación como representantes de los intereses locales por parte del vecindario, pues ambos formaban parte del Ayuntamiento Popular de Madrid. La información sobre los candidatos ha sido obtenida de la consulta de varios periódicos (El Imparcial, La Iberia, La Correspondencia de España). 
María Rivero, miembro de las juntas provisional y superior revolucionaria y máximo responsable del gobierno municipal, figuró en ocho de cada diez papeletas que se depositaron en las urnas. Los vecinos tuvieron clara la inclusión de su alcalde en las papeletas que depositaron en las urnas, pero, a juzgar por la oscilación de los resultados, dieron lugar a combinaciones muy variadas. En este comportamiento electoral podían jugar un papel decisivo tanto los periódicos, que anunciaron varias candidaturas monárquico-democráticas distintas, como los vecinos, que decidían tachar algunos nombres de las que ya estaban impresas sustituyéndolos por el de personalidades de gran reconocimiento social en sus barrios, aprovechando el sistema de listas abiertas.

En Palacio, los miembros de la candidatura oficial eran ampliamente conocidos por su actividad benefactora en las filas del progresismo (Manuel López Silva, visitador de los Asilos de San Bernardino; José Cerdeiras, panadero residente en el barrio de Álamo; y Francisco Díez Zorita, cirujano-médico) o por su intervención en anteriores comicios municipales (Baltasar Gemme). Los monárquico-democráticos presentaron una organización más eficaz en este enclave, visible en las reuniones que se celebraron en el comité electoral presidido por Joaquín Aguirre y en las tareas que este emprendió para conocer a la población con derecho electoral a través del padrón ${ }^{88}$.

Gráfico 12. Tendencia de voto por candidaturas en los barrios del distrito de Palacio

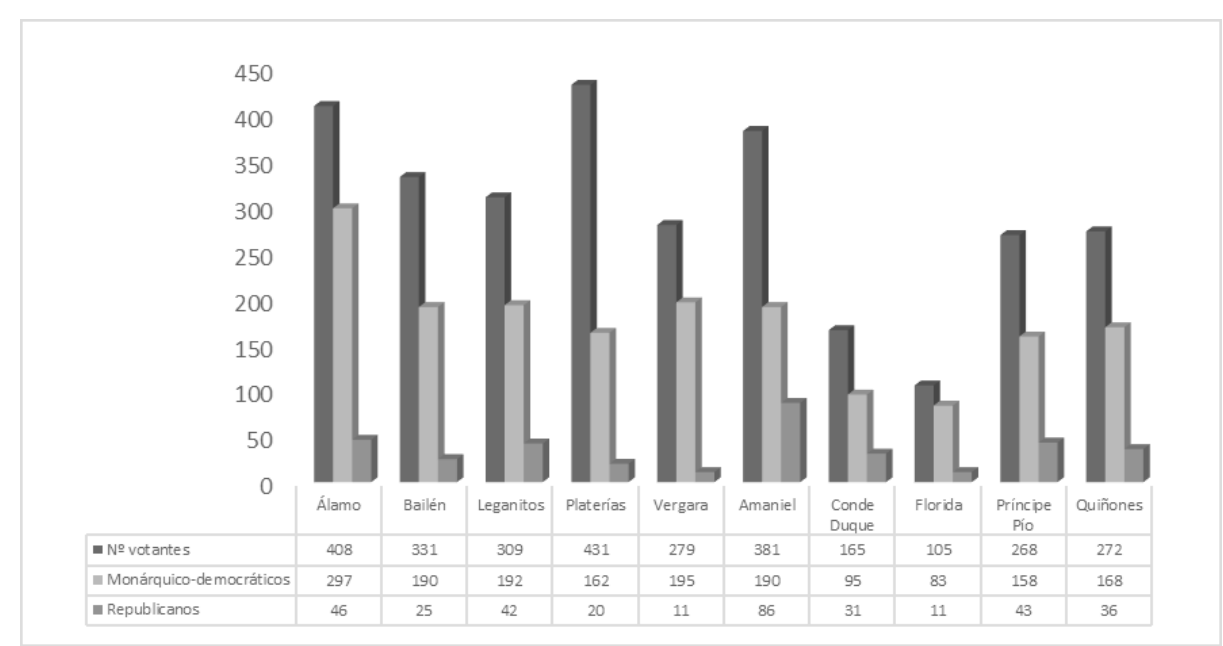

Leyenda: Los votos monárquico-democráticos son los logrados por Baltasar Gemme y Fuentes y los republicanos, los obtenidos por Manuel Galiano. AVM, Secretaría, 4-444-2

${ }^{88}$ La Correspondencia de España, 13 de noviembre de 1868. 
En cuanto a Audiencia, el triunfo de la candidatura oficial monárquicodemocrática formada por Manuel Becerra, Francisco García Martínez, Vicente Tabernilla y Juan Manuel Ranero fue absoluto. El prestigio acumulado por Becerra con su participación en las jornadas revolucionarias de 1848 y 1854 fue clave para abrir una notable brecha en número de votos con respecto a sus compañeros de lista. Recibido con grandes honores por la población a su regreso del exilio parisino, el vecindario le consagró con un apoyo sin fisuras. Pese a todo, esas diferencias también tuvieron que ver con la circulación de candidaturas distintas en las que junto a Becerra aparecían otros progresistas como el comerciante Francisco Somalo, cuyo establecimiento de paños se ubicaba en la Plaza de la Constitución (actual Plaza Mayor), José Fernández Villasante (dueño de una bisutería en la calle de Toledo) e Ignacio Santiago Sánchez. De nuevo, el desconocimiento de reglas básicas del proceso electoral dibujaba escenarios distintos en algunos barrios, y principalmente en los situados en la periferia como Segovia y Puente de Segovia donde Somalo apareció como candidato más votado.

Gráfico 13. Tendencia de voto por candidaturas oficiales en los barrios del distrito de Audiencia

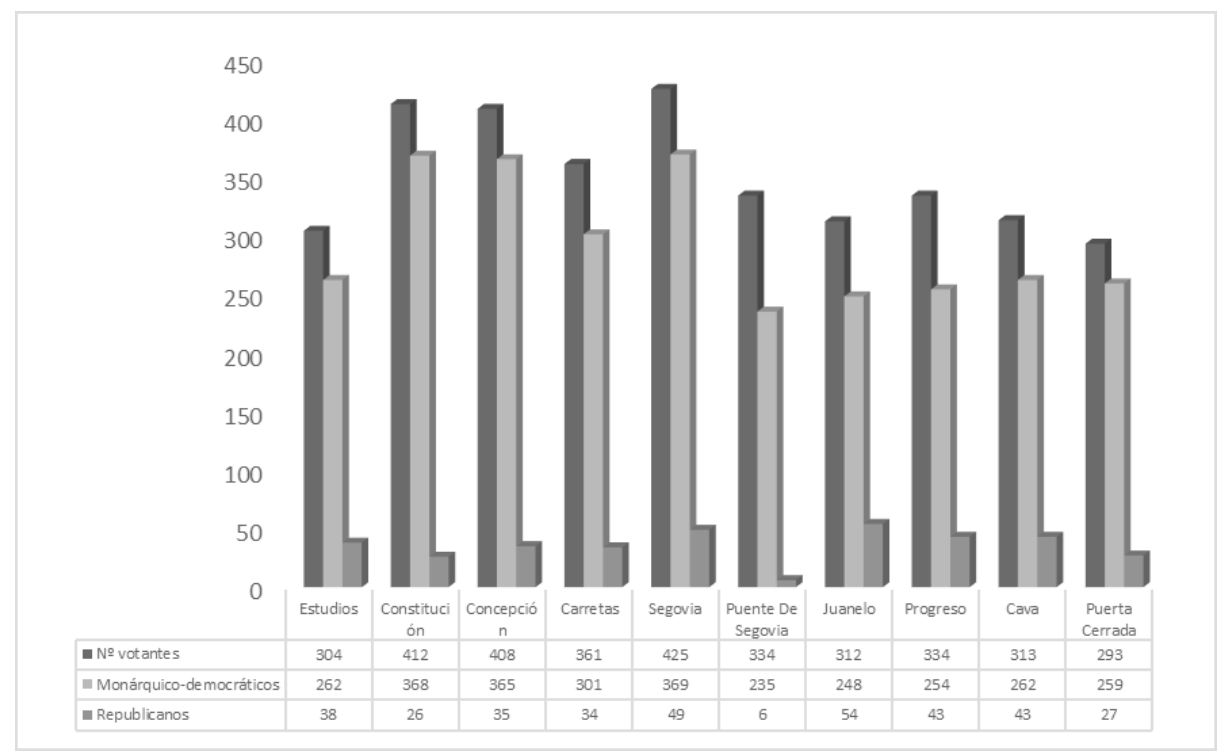

Leyenda: Los votos monárquico-democráticos se corresponden con los obtenidos por Manuel Becerra y los republicanos, por Eduardo Sánchez Rubio. AVM, Secretaría, 4-454.

Lo ocurrido en el distrito de Hospicio presentó grandes similitudes con lo visto en Congreso. Llama la atención que se repitiera el triunfo de Rivero, seguido por figuras decisivas en la movilización progresista de este espacio como José Abascal, de quien se dijo que costeó la organización de círculos y comités y buena parte 
de las multas impuestas a los periódicos liberales durante la etapa moderada a partir de lo que ganaba como contratista de obras; el catedrático de Historia Natural Manuel María José de Galdo; el propietario José Mengíbar y Juan Balín. La duplicidad del nombre de Rivero en la candidatura de ambos distritos se atribuyó a las "grandes simpatías que al Pueblo de Madrid inspira su dignísimo alcalde» y a la "general estimación y confianza que sus nobles dotes han merecido». La Iberia destacó la tendencia observada entre los electores del distrito integrándole en las candidaturas impresas, independientemente del signo político de las mismas. Al considerarse inútil elegirle edil en dos circunscripciones al mismo tiempo, se decidió suspender sus votos durante la realización del escrutinio final ${ }^{89}$.

Significativo es, por último, el panorama advertido en el distrito de Centro. Su mezcolanza social (deudora de un modelo residencial en el que primaba la segregación vertical o en altura) permitió que los republicanos obtuvieran resultados aceptables en determinados barrios. Dentro de su candidatura la personalidad más relevante era la de Antonio Caramés, vendedor de carnes en la Plaza de Herradores ${ }^{90}$. Durante los años anteriores había formado parte del Comité Democrático de Madrid. Con la llegada de la Revolución mostró una participación activa en esta demarcación, tal y como sugiere su presencia en la junta provisional del distrito formada el 29 de septiembre. Junto a él se encontraban otros nombres conocidos dentro del círculo democrático madrileño como Manuel Muñoz y el boticario Liborio Montejo, distinguido por su papel en el cuerpo de profesores nombrado para las consultas públicas de las casas de socorro a comienzos de los sesenta. Menos conocidos por sus experiencias políticas eran Francisco Martínez y Gregorio Pérez Altemir, que cerraban la candidatura.

El análisis de los candidatos monárquico-democráticos permite comprobar cómo la Junta directiva electoral del distrito optó por la designación de figuras de notable reconocimiento social. Para Simón Pérez la implantación del sufragio universal no supuso grandes cambios en lo que respectaba a sus derechos electorales anteriores. Su nombre siempre aparecía en las listas de elegibles, lo que le permitió ser concejal a finales de la época isabelina. El liderazgo que ejercía en la candidatura venía determinado por la iniciativa mostrada en los primeros días de la revolución, liderando la junta interina del distrito, y por el mantenimiento del control del orden público en los barrios de esta zona tras ser designado teniente-alcalde del Ayuntamiento Popular ${ }^{91}$. Junto a él aparecía

89 La lberia, 22 de diciembre de 1868.

90 Caramés habitaba en el número 18 de la calle del Arenal, pagando 300 reales mensuales por el alquiler del 4o piso del inmueble. En: AVM, Estadística, Padrón de 1868.

${ }^{91}$ Simón Pérez tenía un negocio de quincalla en los pisos bajo y entresuelo del inmueble número 1 de la calle Mayor. Por su alquiler, desembolsaba al mes 2.000 reales. Allí vivía junto a su mujer, su hijo y un sobrino, dos dependientes de la tienda y una sirvienta. Fuente: 
Julián Iruela, que también contaba con una amplia trayectoria en la junta directiva electoral progresista del distrito. Lo mismo se podía decir del boticario Félix Borrell, residente en uno de los pisos recientemente construidos tras la reforma de la Puerta del Sol valorado en 3.800 reales mensuales ${ }^{92}$, o de Agustín Pinedo, platero de profesión y miembro de la primera junta revolucionaria interina del distrito.

Las actas del distrito corroboran el triunfo de los candidatos monárquicodemocráticos, pero los resultados adquieren un matiz confuso. Lo lógico es que la victoria de Simón Pérez en cada uno de los barrios del distrito hubiera llegado acompañada por votaciones elevadas para quienes figuraban junto a él en la candidatura, pero no siempre fue así. La existencia de un sistema de listas abiertas fue decisiva para que Agustín Pinedo se quedara sin acta de concejal. Esta quedó en manos de Santiago Ortega Cañamero, al que en ningún momento se mencionó como candidato en prensa. Su labor como inspector del cuerpo de beneficencia ya era encomiable desde principios de la década de los sesenta, especialmente por la voluntad mostrada a la hora de regularizar su organización planteando reformas para la renovación de las casas de socorro ${ }^{93}$. En 1861 fue nombrado académico numerario de medicina y en 1865 se hizo con la dirección del hospital provisional de enfermos de cólera en el distrito de Chamberí. Cuando en diciembre de 1868 decidió probar suerte en la aventura política, la popularidad adquirida durante el decenio anterior le brindó un notable apoyo por parte de los vecinos del distrito, si bien el grueso de sus electores pertenecían a los barrios de Jacometrezo y Abada, que conocía a la perfección por encontrarse su residencia entre esos dos puntos.

Una de las consecuencias de la fragilidad del sistema político se reflejaba en los altos porcentajes de voto de ciertos candidatos independientes en algunos barrios. Entre ellos se encontraban el impresor José de Rojas, con establecimiento en el barrio de Jacometrezo, y Francisco Delgado, industrial con negocio en el número 53 de la calle de Tudescos. Las altas votaciones que alcanzaron en sus zonas de origen, apartadas de la lógica del resto de barrios, permiten corroborar la hipótesis de que la emisión del sufragio en estas elecciones estaba fuertemente determinada por la ascendencia que el candidato podía tener entre sus vecinos. La política dependía de prácticas y representaciones sociales deudoras de la identificación del individuo con un grupo de trabajadores o una comunidad concreta, tendencia que se mantendría durante todo el siglo $x \mathrm{XX}^{94}$.

AVM, Estadística, Padrón de 1868.

\footnotetext{
92 AVM, Estadística, Padrón de 1868.

93 La Discusión, 16 de enero de 1861.

${ }^{94}$ Luis, 2013, pp. 51-69.
} 


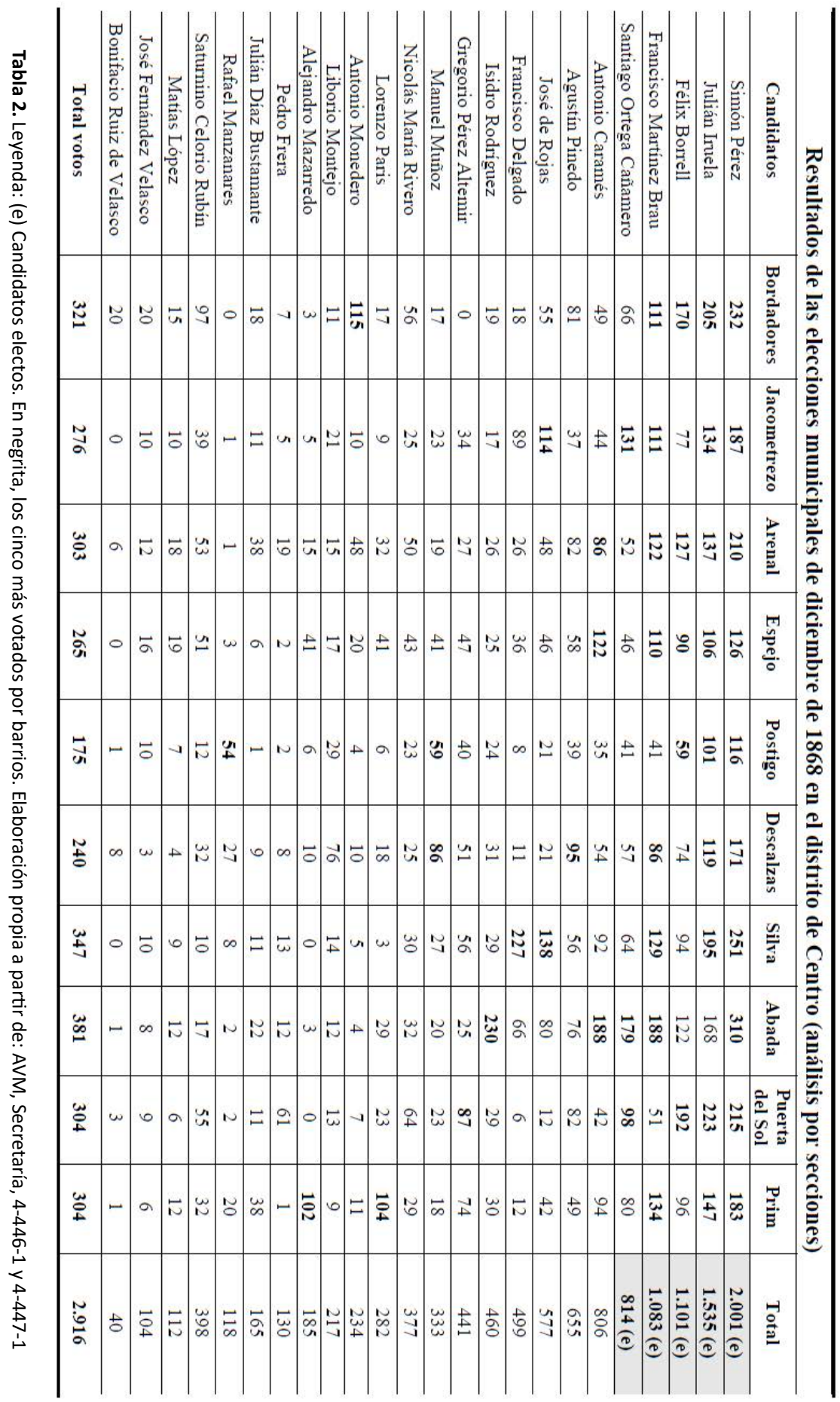


Los republicanos solo triunfaron en doce de los cien barrios que conformaban la división administrativa de Madrid. Su radio de acción se limitó a áreas muy próximas entre sí, salvo en el caso del barrio de Delicias. Los electores de estas zonas no votaron en función de los beneficios que podrían obtener a partir del triunfo de una u otra candidatura, más teniendo en cuenta que en ningún caso se sacaron a escena programas que planteasen mejoras en sus condiciones de vida. Todavía no se habían forjado actitudes políticas ni mecanismos de identificación partidaria en un vecindario que, en la mayoría de los casos, ejerció su derecho electoral por primera vez. De este modo, quizás sería más oportuno señalar que la población de esos barrios de incipiente tendencia republicana votó inducida por el esquema de relaciones sociales interpersonales que habían desarrollado en sus calles en el marco de un proceso de convivencia cotidiana. En este sentido, un vecindario poco sofisticado desde un punto de vista político y desconocedor de las reglas del juego electoral ejerció el voto guiado por los faros que les orientaron hacia las urnas ${ }^{95}$. Estos fueron los comités, los círculos y los clubes republicanos que actuaron en estas áreas, desarrollando una actividad más intensa que en el resto de la ciudad.

Lo anteriormente señalado explica que los electores republicanos de esos barrios y de otros colindantes fuesen los más activos a la hora de presentar reclamaciones a las juntas de escrutinio tras la jornada electoral. Su incipiente adoctrinamiento les llevó a denunciar la impresión de nombres incompletos o con errores en las papeletas monárquico-democráticas, la presencia en estas de lemas políticos o las infracciones registradas en los horarios de apertura de ciertos colegios ${ }^{96}$. En otros casos, las protestas llegaron determinadas por la supuesta incapacidad legal de algunos candidatos. Otra de las infracciones que se vigilaron con gran cuidado por parte de la candidatura republicana aludía a la posible concurrencia de empleados utilizados como muñidores electorales por capataces dependientes del consistorio. Solo se presentó un episodio de estas características en el barrio de Dos de Mayo (Universidad) cuando se descubrió a varios empleados en las obras del Canal de Isabel II acudiendo en cuadrilla al colegio para votar la candidatura monárquico-democrática ${ }^{97}$. Cuando un grupo de electores republicanos de la zona descubrió la artimaña, procedió a su detención y dio orden desde la mesa para que fueran puestos a disposición del Juez de Primera Instancia del distrito.

${ }^{95}$ Se sigue aquí el modelo explicativo de Mayer, quien señaló que dichos faros provendrían del comportamiento y los valores de sus grupos y actores sociales de referencia o pertenencia. En: Mayer, 2006.

${ }^{96}$ AVM, Secretaría, expedientes 4-444-2, 4-446-1, 4-447-1 y 4-454-1.

${ }_{97}$ AVM, Secretaría, expediente 4-445-1. 
Gráfico 14. Mapa de tendencias de voto en las elecciones municipales de 1868

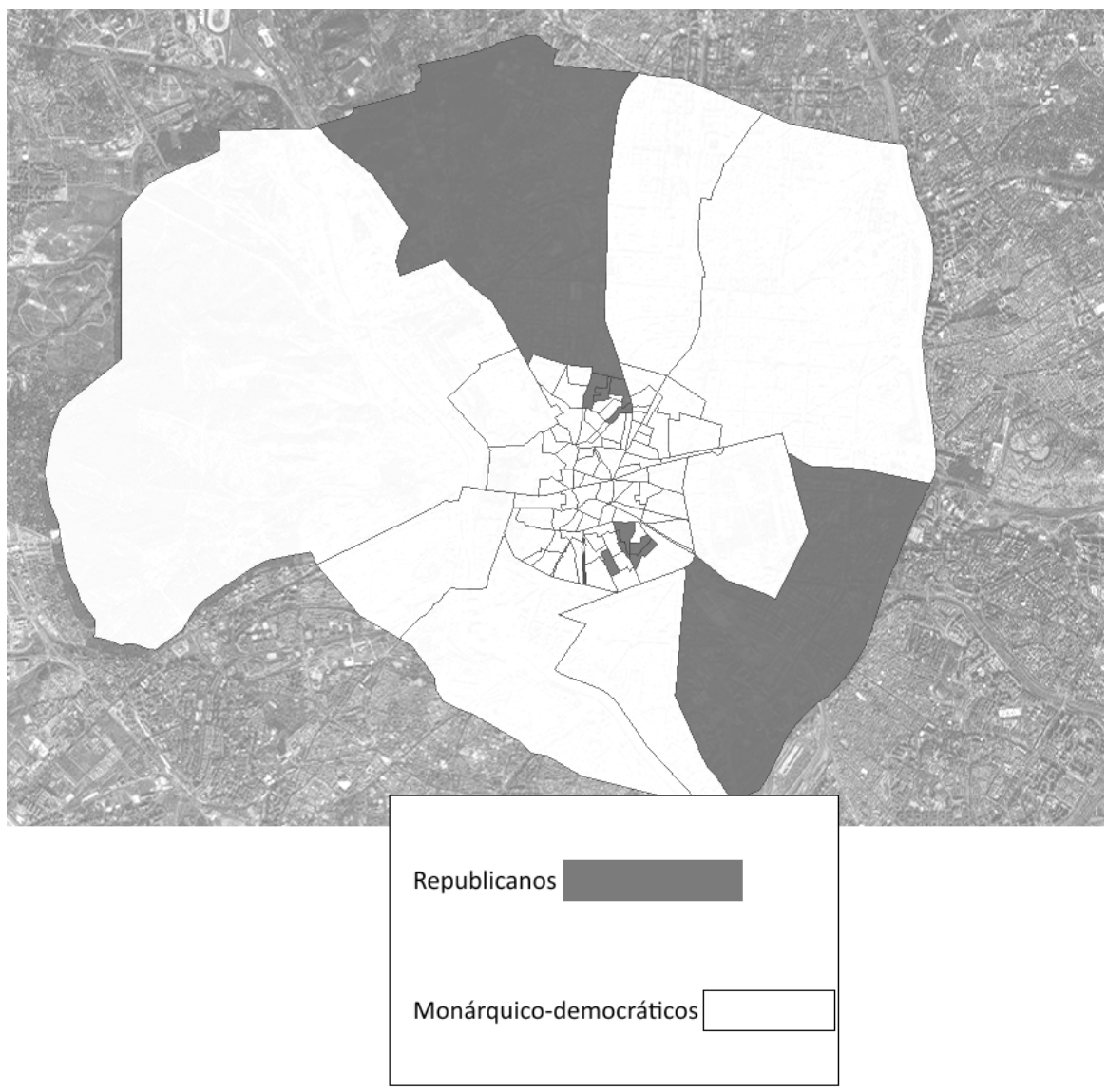

Fuente: Elaboración propia a partir de las actas electorales consultadas en: AVM, Secretaría.

Pese a todo, el grado de libertad con el que los candidatos republicanos actuaron en estas elecciones solo se vio emborronado por lo ocurrido en algunas secciones de Buenavista. En los barrios de Almirante y Libertad, los electores Juan Domingo Pinedo, Juan Manuel Jaén y Miguel González Pardo expresaron al presidente de la mesa sus quejas considerando que se había obstaculizado su actividad tanto por las autoridades municipales como por votantes monárquico-democráticos ${ }^{98}$. Pero más allá de estas argumentaciones, no se emitieron reclamaciones contra posibles injerencias gubernamentales. La ausencia de infracciones graves es una consecuencia más de la ley electoral establecida, que por su carácter innovador impedía que se hubieran desarrollado los medios necesarios para ejercer un control efectivo sobre el electorado.

98 AVM, Secretaría, expediente 4-448-3 y AVM, Secretaría, Libro de Actas del Ayuntamiento Popular de Madrid, 27 de diciembre de 1868. 


\section{CONCLUSIONES}

El 1 de enero de 1869, Nicolás María Rivero renovaba su alcaldía tras ser elegido a pluralidad de votos por los nuevos concejales de Madrid. En su primer discurso expresó su satisfacción por los resultados de unos comicios municipales en los que la población utilizó por primera vez el derecho a un voto ampliamente restringido durante la etapa precedente. Rivero no dudó en señalar que lo más destacado de esa cita había sido su «tranquilidad, legalidad y solemnidad» y la consideró "la consagración de una doctrina, la del sufragio universal, calumniada en años anteriores ${ }^{99}$.

Las elecciones municipales de 1868 deben ser entendidas como una cita en la que los madrileños no votaron en función del programa que ofrecían los partidos, sino movidos por criterios individuales determinados por el prestigio alcanzado durante las primeras jornadas revolucionarias por quienes después se convirtieron en candidatos a las concejalías. A nadie debía extrañar que en la lista de los concejales más votados se encontrasen Manuel Becerra y Nicolás María Rivero, siendo este el único que había ocupado cargos en la Junta Provisional de Gobierno, en la Junta Superior Revolucionaria y en el Ayuntamiento Popular de Madrid en el intervalo que siguió desde los sucesos revolucionarios a los comicios. Al margen de Rivero, cuatro de los nuevos ediles habían figurado en la lista de la Junta Revolucionaria interina, cuatro en la superior que se formó a continuación y quince resultaron designados para las concejalías que funcionaron hasta el 31 de diciembre de 1868. La hipótesis de que los comicios municipales sirvieron para corroborar el orden político establecido con la Septembrina también resulta evidente si se observa la procedencia del resto de concejales del nuevo Ayuntamiento. Veintiuno de ellos habían formado parte de las primeras juntas revolucionarias constituidas en los distritos tras el nombramiento de la provisional de Gobierno (tabla 3). Prácticamente todos vieron reconocido el arraigo político atesorado durante aquellos meses y la amplitud del nuevo juego electoral con el establecimiento del sufragio universal.

${ }_{99}$ AVM, Libro de Actas del Ayuntamiento de Madrid, 1 de enero de 1869. 


\begin{tabular}{|c|c|c|c|c|c|c|c|c|c|c|c|c|c|c|c|}
\hline Concejal & \begin{tabular}{|l|} 
No \\
votos \\
\end{tabular} & Distrito & JID & $C D$ & JRIM & JSRM & APM & Concejal & \begin{tabular}{|l|} 
№ \\
votos \\
\end{tabular} & Distrito & JID & $C D$ & JRIM & JSRM & APM \\
\hline $\begin{array}{l}\text { Manuel } \\
\text { Becerra }\end{array}$ & 2.923 & Audiencia & & & & $v$ & & $\begin{array}{l}\text { Estanislao } \\
\text { Figueras }\end{array}$ & 916 & Hospital & v & & v & & $\begin{array}{lll}v & l & l\end{array}$ \\
\hline $\begin{array}{l}\text { Vicente } \\
\text { Tabernilla }\end{array}$ & 1.971 & Audiencia & & & & & & \begin{tabular}{|l|} 
Pedro \\
Pallarés \\
\end{tabular} & 823 & Hospital & $v$ & & & & \\
\hline $\begin{array}{l}\text { Francisco } \\
\text { García } \\
\text { Martínez }\end{array}$ & 1.910 & Audiencia & & & & & & $\begin{array}{l}\text { Patricio } \\
\text { Lozano }\end{array}$ & 826 & Hospital & & & & & v \\
\hline $\begin{array}{l}\text { Juan } \\
\text { Manuel } \\
\text { Ranero }\end{array}$ & 1.872 & Audiencia & v & & & & $v$ & $\begin{array}{l}\text { Julián } \\
\text { Viñas }\end{array}$ & 1.000 & Hospital & v & & & & \\
\hline $\begin{array}{l}\text { Santiago } \\
\text { Olózaga }\end{array}$ & 1.452 & Buenavista & v & v & & & & \begin{tabular}{|l|} 
Camilo \\
Laorga
\end{tabular} & 974 & Inclusa & & $v$ & & v & \\
\hline $\begin{array}{l}\text { Felipe } \\
\text { Ibarra }\end{array}$ & 1.116 & Buenavista & & v & & & & \begin{tabular}{|l|} 
Joaquín \\
Fernández \\
Albert
\end{tabular} & 1.051 & Inclusa & & $v$ & & & $v$ \\
\hline $\begin{array}{l}\text { Ángel Fdez } \\
\text { de los Ríos }\end{array}$ & 1.848 & Buenavista & & v & & & & \begin{tabular}{|l|} 
Manuel \\
Bravo
\end{tabular} & 1.044 & Inclusa & & $v$ & & & \\
\hline $\begin{array}{l}\text { Casimiro } \\
\text { Gil }\end{array}$ & 1.405 & Buenavista & & & & & & \begin{tabular}{|l|} 
Román \\
Ortiz
\end{tabular} & 828 & Inclusa & & $v$ & & & \\
\hline $\begin{array}{l}\text { José García } \\
\text { Cachena }\end{array}$ & 1.229 & Buenavista & v & $v$ & & & & \begin{tabular}{|l|} 
Juan \\
Antonio \\
Sánchez \\
Blanco \\
\end{tabular} & 1.904 & Latina & $\mathrm{v}$ & & & & $v$ \\
\hline $\begin{array}{l}\text { Simón } \\
\text { Pérez }\end{array}$ & 2.001 & Centro & $v$ & & & & v & \begin{tabular}{|l|} 
Manuel \\
Prieto
\end{tabular} & 2.111 & Latina & $\mathrm{v}$ & & & & $v$ \\
\hline $\begin{array}{l}\text { Francisco } \\
\text { Martínez } \\
\text { Brau }\end{array}$ & 1.083 & Centro & & & & & & $\begin{array}{l}\text { Julián } \\
\text { Sevilla }\end{array}$ & 1.702 & Latina & $\begin{array}{lll}v & l & l\end{array}$ & $v$ & & & \\
\hline $\begin{array}{l}\text { Julián } \\
\text { Iruela }\end{array}$ & 1.535 & Centro & & & & & & \begin{tabular}{|l|} 
Alfonso \\
Sánchez \\
Talavera \\
\end{tabular} & 1.721 & Latina & v & & & & v \\
\hline $\begin{array}{l}\text { Santiago } \\
\text { Ortega } \\
\text { Cañamero }\end{array}$ & 814 & Centro & & & & & & \begin{tabular}{|l|} 
Eduardo \\
Gasset Y \\
Artime \\
\end{tabular} & 2.279 & Latina & $v$ & & & & $\mathrm{v}$ \\
\hline Félix Borrell & 1.101 & Centro & & & & & & $\begin{array}{l}\text { Baltasar } \\
\text { Gemme }\end{array}$ & 1.731 & Palacio & $\mathrm{v}$ & & & & \\
\hline \begin{tabular}{l|} 
Nicolás \\
María \\
Rivero \\
\end{tabular} & 2.724 & Congreso & & & $v$ & v & $\mathrm{v}$ & $\begin{array}{l}\text { José } \\
\text { Cerdeiras }\end{array}$ & 1.710 & Palacio & v & & & & \\
\hline $\begin{array}{l}\text { Fernando } \\
\text { Hidalgo } \\
\text { Saavedra }\end{array}$ & 1.192 & Congreso & & & & v & & \begin{tabular}{|l|} 
Manuel \\
López De \\
Silva \\
\end{tabular} & 1.714 & Palacio & $\mathrm{v}$ & & & & \\
\hline $\begin{array}{l}\text { Fernando } \\
\text { Jaquete }\end{array}$ & 1.121 & Congreso & & & & & & \begin{tabular}{|l|} 
Francisco \\
Díez Zorita \\
\end{tabular} & 1.441 & Palacio & & & & & \\
\hline $\begin{array}{l}\text { José Luis } \\
\text { Alvareda }\end{array}$ & 1.284 & Congreso & & & & & v & \begin{tabular}{|l|} 
Manuel \\
Soriano \\
\end{tabular} & 1.602 & Palacio & $v$ & $v$ & & & \\
\hline $\begin{array}{l}\text { Manuel } \\
\text { Ma José de } \\
\text { Galdo }\end{array}$ & 1.966 & Hospicio & v & & & & $v$ & \begin{tabular}{|l|} 
José \\
Rodríguez \\
Villabrille \\
\end{tabular} & 1.529 & Universidad & v & & & & $v$ \\
\hline $\begin{array}{l}\text { José } \\
\text { Abascal } \\
\text { Carredano }\end{array}$ & 1.945 & Hospicio & & & v & & $v$ & \begin{tabular}{|l|} 
Ruperto \\
Fernández \\
de las \\
Cuevas \\
\end{tabular} & 1.406 & Universidad & & & v & & v \\
\hline $\begin{array}{l}\text { José } \\
\text { Mengíbar }\end{array}$ & 1.236 & Hospicio & $v$ & & & & & \begin{tabular}{|l|} 
Antonio \\
Vallés \\
\end{tabular} & 1.478 & Universidad & & & $v$ & & \\
\hline Juan Balín & 1.404 & Hospicio & $v$ & & & & & \begin{tabular}{|l|} 
Gregorio \\
De Las \\
Pozas \\
\end{tabular} & 1.528 & Universidad & $\mathrm{v}$ & & & $\mathrm{v}$ & \\
\hline $\begin{array}{l}\text { Diego } \\
\text { López } \\
\text { Santiso }\end{array}$ & 917 & Hospital & & & & & v & $\begin{array}{l}\text { Leandro } \\
\text { Marichalar }\end{array}$ & 828 & Inclusa & & $\mathrm{v}$ & & & \\
\hline
\end{tabular}

Tabla 3. Precedentes políticos de los concejales del Ayuntamiento de Madrid elegidos en los comicios municipales de diciembre de 1868. Leyenda: JID (Juntas Interinas Revolucionarias de distrito); CD (comités de distritos); JRIM (Junta Revolucionaria Interina de Madrid); JSRM (Junta Superior Revolucionaria de Madrid); APM (Ayuntamiento Popular de Madrid). 


\section{BIBLIOGRAFÍA}

Aguilhon, M. (1992). 1848 ou l'apprentissage de la République: 1848-1852. Paris: Seuil.

Alfaro, M. I. (1871-1876). Historia de la interinidad española, Vol. II. Madrid: Est. Tip. de la Vda. e Hijos de M. Álvarez.

Arias, E. (2010). La revolución de 1868 en Sevilla. Sevilla: Ayuntamiento de Sevilla.

Caballero, M. (1999). El derecho de representación: sufragio y leyes electorales. Ayer, 34, 41-63.

Castro, D. (1994). Unidos en la adversidad, unidos en la discordia: el Partido Demócrata, 1849-1868. En N. Townson (ed.), El republicanismo en España (1830-1977) (pp. 59-85). Madrid: Alianza.

De Bona, F. J. (1996). Anuario administrativo y estadístico de la provincia de Madrid para el año de 1868 (edición facsímil). Madrid: Consejería de Hacienda.

De la Fuente, G. y Serrano, R. (2005). La revolución gloriosa. Un ensayo de regeneración nacional (1868-1874). Madrid: Biblioteca Nueva.

De la Fuente, G. (2000). Los revolucionarios de 1868. Elites y poder en la España liberal. Madrid: Marcial Pons.

Díez de Baldeón, A. (1993). El nacimiento de un barrio burgués. Argüelles en el siglo XIX. NORBA: Revista de arte, 13, 231-268.

Eiras, A. (2015 [1961]). El Partido Demócrata español. 1849-1873. Madrid: Ediciones 19.

Esteban, M. Á. (1994). De la esperanza a la frustración, 1868-1873. En N. Townson (ed.), El republicanismo en España (1830-1977) (pp. 87-112). Madrid: Alianza, 1994.

Estrada, M. (1999). El significado político de la legislación electoral en la España de Isabel II. Santander: Universidad de Cantabria.

Fernández, A. (2003). El estreno del sufragio universal en Madrid (1869). Cuadernos de Historia Contemporánea, n.o extraordinario, 71-83. 
Flaquer, R. (2007). Ciudadanía civil y ciudadanía política en el siglo XIX. El sufragio. En M. Pérez Ledesma (coord.), De súbditos a ciudadanos: una historia de la ciudadanía en España (pp. 59-102). Madrid, CEPC.

Fruci, G. L. (2008). II sacramento dell'unitá nazionale. Linguaggi, iconografía e patriche dei plebicisti risorgimentali (1848-1870). En A. M. Banti y P. Ginsborg (dirs.), Storia d'Italia. Annali. Il Risorgimento (pp. 567-605). Turín: Einaudi.

Garrigou, A. (1991). Le brouillon du suffrage universel. Archéologie du décret du 5 mars 1848. Genèses, 6, 161-178.

Gil Novales, A. (1980). La revolución de 1868 en el Alto Aragón. Zaragoza: Guara Editorial.

Gutiérrez, R. A. (1987). La República y el orden. Burguesía y republicanismo en Alicante (1868-1893). Tesis Doctoral, Universidad de Alicante.

Gutiérrez, R. A. y Zurita, R. (1999). Canvi polític i mobilització electoral en la revolució del 1868. Recerques, 39, 31-54.

Gutiérrez, R. A. (2001). Sociabilidad política, propaganda y cultura tras la revolución de 1868. Los clubes republicanos en el Sexenio Democrático. Ayer, 44, 151-172.

Hennessy, C. (2010 [1962]). La República Federal en España. Pi i Margall y el movimiento republicano federal, 1868-1874. Madrid: Los Libros de la Catarata.

Heras, P. A. (1981). La revolució de Setembre de 1868 a Tarragona. Tarragona: Ajuntament.

Herrán, J. (1986). La Gloriosa en Cádiz: de la Revolución de 1868 a la Constitución de 1869. Cádiz: Fundación Municipal de Cultura.

Huard, R. (1991). Le suffrage universel en France, 1848-1946. Aubier.

Janué, M. (2002). El fracaso del Sexenio en Cataluña. En R. Serrano (dir.), España, 1868-1874. Nuevos enfoques sobre el Sexenio Democrático (pp. 259-289). Valladolid: Junta de Castilla y León.

Janué, M. (2002). Els politics en temps de revolució. La vida política a Barcelona durant el Sexenni revolucionari (1868-1873). Vic: Eumo Editorial. 
Jerez, J. (2008). El sexenio democrático en Albacete: juntas y procesos electorales (1868-1873). Tesis doctoral, Universidad de Castilla La Mancha.

Kahan, A. S. (2003). Liberalism in nineteenth-century Europe: the political culture of limited suffrage. Basingstoke: Palgrave MacMillan.

Luis, J.-P. (2013). España y los modelos occidentales de nacimiento de la política moderna. En VV. AA., El nacimiento de la política en España (1808-1869) (pp. 51-69). Madrid: Fundación Pablo Iglesias.

Martínez, A. (1989). La representatividad municipal española. Historia legislativa y régimen vigente. Murcia: Universidad de Murcia.

Mayer, N. (2006). Qui vote pour qui et pourquoi? Les modèles explicatifs du choix électoral. Pouvoirs. Revue Française d'Études Constitutionnelles et Politiques, $120,17-28$.

Monlleó, R. (1996). La Gloriosa en Valencia (1864-1869). Valencia: IVEI.

Monlleó, R. (2001). Republicanos contra monárquicos. Del enfrentamiento electoral y parlamentario a la insurrección federal de 1869. Ayer, 44, 55-82.

Morales, M. (2002). Cultura política y sociabilidad en la democracia republicana. En R. Serrano (dir.), España 1868-1874. Nuevos enfoques sobre el Sexenio Democrático (pp. 211-234). Valladolid: Junta de Castilla y León.

Navarro, J. (2004). Territorialidad y proceso electoral en el Sexenio revolucionario: el municipio de Murcia. Anales de Historia Contemporánea, 20, 329-354.

Noiret, S. (ed.) (1990). Political strategies and electoral reforms: origins of voting systems in Europe in the 19th and 20th centuries. Baden-Baden: Nomos Verlagsgesellschaft.

Offerlé, M. (1993). Un homme, une voix ? Histoire du suffrage universel. Paris: Gallimard.

Ollero, J. L. (2006). Tan cerca, tan lejos: Sagasta y los progresistas frente al republicanismo en el Sexenio Democrático. Espacio, Tiempo y Forma. Serie V, Historia Contemporánea, 18, 91-109.

Pallol, R., Carballo, B. y Vicente, F. (2010). Inmigración y mercado de trabajo en el Madrid de la segunda mitad del siglo XIX. Revista de Demografía Histórica, 28(1), 131-166. 
Pallol, R. (2013). Una ciudad sin límites. Transformación urbana, cambio social y despertar político en Madrid 1860-1875. Madrid: Los Libros de la Catarata.

Pérez Roldán, C. (2001). El Partido Republicano Federal, 1868-1874. Madrid: Endymion.

Peyrou, F. (2008). Tribunos del pueblo: Republicanos y demócratas en la España isabelina. Madrid: CEPC.

Przeworski, A. (2009). Conquered or Granted? A History of Suffrage Extensions. British Journal of Political Science, 39(2), 291-321.

Reclús, E. (2007). Impresiones de un viaje por España en tiempos de Revolución. Logroño: Pepitas de Calabaza.

Rodríguez Chumillas, I. (2002). Vivir de las rentas. El negocio del inquilinato en el Madrid de la Restauración (pp. 150-152). Madrid: Los Libros de la Catarata.

Rodríguez Solís, E. (1893). Historia del Partido Republicano Español, tomo II. Madrid: Imprenta de Fernando Cao y Domingo de Val.

Romanelli, R. (ed.) (1998). How did they become voters? The History of Franchise in Modern European Representation. La Hague: Kluwer Law International.

Romeo, M. C. (2013). Un fenómeno no previsto: los partidos políticos. En VV. AA., El nacimiento de la política en España (1808-1869) (pp. 97-116). Madrid: Fundación Pablo Iglesias.

Rosanvallon, P. (1992). Le sacre du citoyen. Paris: Gallimard.

Rosanvallon, P. (1998). Le peuple introuvable. Paris: Gallimard.

Rubio, C. (1869). Historia filosófica de la revolución española de 1868, tomo II. Madrid: Imprenta y Librería de M. Guijarro.

Sánchez Illán, J. C. (1996). Los Gasset y los orígenes del periodismo moderno en España, «El Imparcial», 1867-1906. Historia y Comunicación Social, 1, 259-276.

Serrano, R. (1992). La revolución de 1868 en Castilla y León. Valladolid: Secretariado de Publicaciones-Universidad de Valladolid. 
Serrano, R. (1995). El sexenio democrático en Zamora: (1868-1874). En J. C. Alba (dir.), Historia de Zamora. Zamora: Diputación de Zamora, vol. III, pp. 151-180.

Sierra, M., Peña, M. A. y Zurita, R. (2010). Electores y elegibles: la representación parlamentaria en la cultura del liberalismo. Madrid: Marcial Pons.

Touya, J. (2002). Madrid, 1850: análisis de un cuerpo electoral restringido: contribución al estudio de las clases medias madrileñas a mediados del siglo XIX, Tesis Doctoral. Madrid: UCM.

Vicente, F. (2015). El Ensanche Sur. Arganzuela, 1860-1931. Los barrios negros. Madrid: Los Libros de la Catarata.

Vilches, J. (2001). Progreso y libertad: el Partido Progresista en la Revolución Liberal española. Madrid: Alianza.

Villanueva, J. R. (1993). El republicanismo turolense durante el siglo XIX (18401898). Zaragoza: Mira Editores.

Villena, R. (1997). El sexenio democrático en la provincia de Ciudad Real. Economía, política y sociedad (1868-1874), Tesis Doctoral. Cuenca: UCLM.

Villena, R. (2001). La crisis del Estado centralista y la administración territorial en el Sexenio. Ayer, 44, 83-108.

Villette, V. (2013). Apprendre à voter sous la lle République. Le suffrage de masse dans le département de la Seine (1848-1851). Paris: Les Indes Savantes.

Viñao, A. (1990). A la cultura por la lectura. Las bibliotecas populares (1869-1885). En Guereña, J. L. y Tiana, A. (coords.), Clases populares, cultura, educación. Siglos XIX y XX (pp. 324-333). Madrid: UNED.

Zurita, R. (2014). El progresismo. Héroes e historia de la nación liberal. En M. C. Romeo y M. Sierra (coord.), Historia de las Culturas Políticas en España y América Latina. Tomo II, La España Liberal, 1833-1874 (pp. 317-346). Madrid: Marcial Pons. 
Página intencionadamente en blanco. 